\title{
Reversible cysteine oxidation in hydrogen peroxide sensing and signal transduction
}

Sarela García-Santamarina, Susanna Boronat and Elena Hidalgo*

Oxidative Stress and Cell Cycle Group, Departament de Ciències Experimentals i de la Salut, Universitat Pompeu Fabra, C/ Dr. Aiguader 88, E-08003 Barcelona, Spain

The first two authors contributed equally to this work

*Corresponding author: Elena Hidalgo, Universitat Pompeu Fabra, C/ Dr. Aiguader 88, E08003 Barcelona, Spain (elena.hidalgo@upf.edu; Tel: 34-93-316-0848; Fax: 34-93-316-

0901)

Funding Source Statement: This work was supported by the Spanish Ministry of Science and Innovation (BFU2012-32045), PLAN E and FEDER, by the Spanish program Consolider-Ingenio 2010 Grant CSD 2007-0020, and by SGR2009-195 from Generalitat de Catalunya (Spain) to E.H. E. H. is recipients of an ICREA Academia Award (Generalitat de Catalunya).

Keywords: redox biology / $\mathrm{H}_{2} \mathrm{O}_{2}$ reactivity / Cys oxidation / $\mathrm{H}_{2} \mathrm{O}_{2}$ sensor / redox proteomics / Pap1 / Yap1 / OxyR / Nrf2 / roGFP 


\section{ABBREVIATIONS}

Reactive oxygen species (ROS)

Oxygen $\left(\mathrm{O}_{2}\right)$

Superoxide $\left(\mathrm{O}_{2}^{-}\right)$

Hydrogen peroxide $\left(\mathrm{H}_{2} \mathrm{O}_{2}\right)$

Hydroxyl radical $(\mathrm{OH})$

Cysteine (Cys)

Sulfenic acid $(\mathrm{SOH})$

Sulfinic $\left(\mathrm{SO}_{2} \mathrm{H}\right)$

Sulfonic $\left(\mathrm{SO}_{3} \mathrm{H}\right)$

Thioredoxin (Trx)

Glutathione (GSH)

Glutaredoxin (Grx)

Peroxiredoxin (Prx)

Nucleophilic substitution type $2\left(\mathrm{~S}_{\mathrm{N}} 2\right)$

Protein tyrosine phosphatase (PTP)

Glyceraldehyde-3-phosphate dehydrogenase (GAPDH)

Glutathione peroxidase (GPx)

Ribonucleotide reductase (RNR)

Phosphoadenylyl sulfate (PAPS)

Trx reductase (TrxR)

Oxidized GSH (GSSG)

Glutathione reductase (GSHR)

Alkaline phosphatase (AP)

Nuclear localization signal (NLS)

Basic-leucine zipper (bZIP)

Cys-rich domain (CRD)

Nuclear export signal (NES)

Antioxidant response elements (ARE)

Amino terminal region (NTR)

Intervening region (IVR)

Double glycine repeat (DGR)

Carboxy-terminal region (CTR)

Redox green fluorescent protein (roGFP)

Enhanced GFP (EGFP)

Trichloroacetic acid (TCA)

S-nitrosylation (SNO)

Iodoacetamide (IAM)

Dithiothreitol (DTT)

Tris (2- carboxyethyl) phosphine hydrochloride (TCEP)

SNO Site Identification (SNOSID)

SNO Resin Assisted Capture (SNO-RAC)

GEL-based Stable Isotope Labeling of Oxidized Cys (GELSILOX)

Isotope coded affinity tag (ICAT)

Isobaric tag for relative and absolute quantitation (iTRAQ) 


\begin{abstract}
Activation of redox cascades through hydrogen peroxide-mediated reversible cysteine oxidation is a major mechanism for intracellular signaling. Understanding why some cysteine residues are specifically oxidized, in competition with other proximal cysteine residues and in the presence of strong redox buffers, is therefore crucial to understand redox signaling. In this review we explore the recent advances in thiol redox chemistry linked to signaling. We describe the last findings in the field of redox sensors, those that are naturally present in different model organisms as well as those that have been engineered to quantify intracellular hydrogen peroxide concentrations. Finally, we provide a summary of the newest approaches developed to study reversible cysteine oxidation at the proteomic level.
\end{abstract}


Reactive oxygen species (ROS) refer to a variety of molecules and free radicals which are produced as normal intermediates in the reductive process of molecular oxygen $\left(\mathrm{O}_{2}\right)$ to water inside cells. Thus, one-electron reduction of $\mathrm{O}_{2}$ produces superoxide anion $\left(\mathrm{O}_{2}^{-}{ }^{-}\right)$, the precursor of many ROS. $\mathrm{O}_{2}^{-} \cdot$ dismutation, either spontaneously or catalyzed by superoxide dismutase, yields hydrogen peroxide $\left(\mathrm{H}_{2} \mathrm{O}_{2}\right)$, a non-radical species. $\mathrm{H}_{2} \mathrm{O}_{2}$ can be partially reduced to hydroxyl radical $(\mathrm{OH})$, one of the strongest oxidants in nature, or fully reduced to water $(1)$.

The highly reactive nature of the different ROS makes them toxic to cells; as a consequence, if not counteracted by antioxidant enzymes or molecules, these can cause irreversible damage to proteins (2), lipids (3), and DNA (4). Nevertheless, in the particular case of ROS reacting with proteins, there is a narrow window in which small fluctuations of their steady-state concentrations may play roles in intracellular signaling (5).

However, not all ROS are equally suited to participate in redox signaling events. Specific physical and chemical properties confer to $\mathrm{H}_{2} \mathrm{O}_{2}$ the most appropriate characteristics for this role. First, it is a quite stable molecule in cells (half-life $10^{-3} \mathrm{~s}$ ), that in spite of being a strong oxidant $\left(\mathrm{E}^{\prime \mathrm{o}} 1.349 \mathrm{~V}\right.$ for its reduction to water at $\left.\mathrm{pH} 7\right)(6)$, kinetic barriers restrain its indiscriminate reactivity with bio molecules. Second, it is able to specifically oxidize certain amino acids (see below) in a target protein in a fast and reversible way. Thus, in general, $\mathrm{H}_{2} \mathrm{O}_{2}$ does not react with amino acid side chains in proteins, and its toxicity is mainly due to its conversion to the more reactive species $\mathrm{OH}$. However, methionine and cysteine (Cys) residues reach higher second-order reaction rates [around $10^{-2} \mathrm{M}^{-1} \mathrm{~s}^{-1}$ for reaction with methionine $(1)$, and are around $20 \mathrm{M}^{-1} \mathrm{~s}^{-1}$ for reactions with low molecular weight thiol compounds (or their corresponding thiolates) at physiological $\mathrm{pH}(7)]$. Oxidation of methionine and Cys to low oxidation states (methionine sulfoxide and sulfenic acid/disulfides, respectively) can be reversed by intracellular reducing systems, but only Cys 
oxidation has been unambiguously described to participate in the activation of $\mathrm{H}_{2} \mathrm{O}_{2}-$ responding pathways [very few examples in the literature suggest methionine oxidation playing a similar regulatory role in signaling (8)]. Accordingly, oxidation of thiols in proteins with $\mathrm{H}_{2} \mathrm{O}_{2}$ to reversible forms can proceed with high rate constants up to $10^{8} \mathrm{M}^{-1} \mathrm{~s}^{-1}$ (9). In fact, this high reactivity of $\mathrm{H}_{2} \mathrm{O}_{2}$ with particular Cys provides the basis by which $\mathrm{H}_{2} \mathrm{O}_{2}$ engages into intracellular signaling cascades (10-12).

In this Review, we discuss the role of $\mathrm{H}_{2} \mathrm{O}_{2}$-dependent reversible Cys oxidation linked to signaling. First, we focus on the reaction mechanism of $\mathrm{H}_{2} \mathrm{O}_{2}$ with thiols from Cys residues, and how specificity is achieved allowing this species to behave in a positive way for signaling purposes. We then describe the pathways required to restore thiol-redox equilibrium once it is altered, that is, the thioredoxin and glutaredoxin systems. We also describe here the best characterized $\mathrm{H}_{2} \mathrm{O}_{2}$ sensors in signaling cascades in both bacteria and eukaryotes, and how their exquisite reactivity with $\mathrm{H}_{2} \mathrm{O}_{2}$ has been exploited to design genetically-encoded reporters of $\mathrm{H}_{2} \mathrm{O}_{2}$ fluctuations. Finally, we discuss some of the current available methodologies to study thiol modifications at the proteome level.

\section{$\mathrm{H}_{2} \mathrm{O}_{2}$ REACTIVITY WITH THIOL GROUPS}

Even though they are not very abundant, Cys residues are over-represented in functional regions of proteins (13). The sulfur atom can be in any oxidation state ranging from +6 to -2 (14), and therefore its oxidation/reduction is an important mechanism of post-translational modification. Thus, low levels of $\mathrm{H}_{2} \mathrm{O}_{2}$ can oxidize the Cys thiol initially to sulfenic acid (SOH). This is a very reactive species, it will rapidly form a disulfide bond or a sulfenamide if there is any thiol or nitrogen available in the vicinity, respectively. Upon higher doses of $\mathrm{H}_{2} \mathrm{O}_{2}$, SOH may become further oxidized to sulfinic $\left(\mathrm{SO}_{2} \mathrm{H}\right)$ or sulfonic $\left(\mathrm{SO}_{3} \mathrm{H}\right)$ acids. The 
oxidized forms $\mathrm{SOH}$, disulfide, and sulfenamide, can be restored to the initial - $\mathrm{SH}$ thanks to specific cellular activities, the thioredoxin (Trx) and the glutathione/glutaredoxin (GSH/Grx) systems (Figure 1). Occasionally, $-\mathrm{SO}_{2} \mathrm{H}$ can be reduced in an energy consuming process by sulfiredoxins, when this species is formed in some members of the family of peroxiredoxins (Prxs) (15-17). Thus, by being oxidized to different forms, Cys residues in proteins can act as sensors of $\mathrm{H}_{2} \mathrm{O}_{2}$, providing cells with a mechanism to sense and respond to changes in the redox environment.

Kinetic barriers govern Cys thiol reactivity with $\mathrm{H}_{2} \mathbf{O}_{2}$. As mentioned above, $\mathrm{H}_{2} \mathrm{O}_{2}$ is a powerful oxidant; however, it generally reacts slowly with thiols in proteins. That is because, although thermodynamically favorable, high energy is required to reach the transition state of the reaction. Hence, $\mathrm{H}_{2} \mathrm{O}_{2}$ reactivity with thiols in Cys residues is mainly governed by kinetics (18). This is an advantage when considering $\mathrm{H}_{2} \mathrm{O}_{2}$ acting as a second messenger, since kinetics and spatial relationships are the only factors governing ROS specificity $(5,19)$. In fact, $\mathrm{H}_{2} \mathrm{O}_{2}$ specific thiol targets, those meant to transmit information, must be competitive not only with any other type of thiols contained in proteins in the milieu but also with the antioxidants supposed to control their redox state. Understanding $\mathrm{H}_{2} \mathrm{O}_{2}$ reactivity with thiol groups is therefore crucial to explain how this species engage into signaling processes.

Reaction of $\mathrm{H}_{2} \mathrm{O}_{2}$ with a thiol group requires first the acid/base deprotonation of the thiol to a thiolate. Once this species is formed, it attacks on the symmetric $\mathrm{H}_{2} \mathrm{O}_{2}$ electrophile through a nucleophilic substitution type $2\left(\mathrm{~S}_{\mathrm{N}} 2\right)$. Thus, the available fraction of thiolate, its stability, and its ability to act as a nucleophile, are major determinants on the reaction rates between these two species. 
The $p K_{a}$ of a thiol group in a Cys residue is directly related to the equilibrium constant of its deprotonation reaction (R-SH $\leftrightarrow \mathrm{R}^{-\mathrm{S}^{-}}+\mathrm{H}^{+} ; K_{a}=\left[\mathrm{H}^{+}\right]\left[\mathrm{R}-\mathrm{S}^{-}\right] /[\mathrm{R}-\mathrm{SH}]$, in which $\left[\mathrm{H}^{+}\right],\left[\mathrm{R}-\mathrm{S}^{-}\right]$, and $[\mathrm{R}-\mathrm{SH}]$ are the equilibrium concentrations in mol/l; and $\left.p K_{a}=-\log K_{a}\right)$. Lowering the $p K_{a}$ of the nucleophilic Cys will increase its thiolate fraction and hence its reactivity. Based on studies of Cys reactivity in enzymes of the Trx family, Roos G et al. (20) determined that hydrogen-bonding interactions of the sulfur atom with the surrounding environment are the main factors stabilizing the negative charge of the thiolate, lowering its $p K_{a}$ as a consequence. Other factors, including solvation and electrostatic effects, are less likely to have an important contribution. However, having a low $p K_{a}$ value is not a guarantee of enhanced reactivity. In fact, factors that stabilize the thiolate species also decrease its nucleophilic character (the availability of the negative charge diminishes), rendering a larger energy to reach the transition state. As a consequence, the effect of lowering the $p K_{a}$ on rate enhancement is more significant at $p K_{a}$ values close to the $\mathrm{pH}$ of the solution $(21,22)$.

In general, the $p K_{a}$ of the sulfhydril group of free Cys, GSH, and of many Cys linked to a protein backbone, especially those buried (23), are around or even higher than 8.5 (24, 25). Thus, these molecules are not very reactive with $\mathrm{H}_{2} \mathrm{O}_{2}$ at physiological $\mathrm{pH}$. However, many are the examples on the literature of acidic sulfhydril groups, especially in solvent exposed Cys residues (13) and in catalytic centers of many enzymes, with different outcomes regarding reactivity with $\mathrm{H}_{2} \mathrm{O}_{2}$. Thus, thiols in proteins with low $p K_{a}$ values, including for instance protein tyrosine phosphatases (PTPs) or glyceraldehyde-3-phosphate dehydrogenase (GAPDH), whose function is modulated by switches in the oxidation status of some of their Cys $(26,27)$, have low reactivity rates, with similar values to those of free Cys or GSH. However, proteins including Prxs or glutathione peroxidases (GPxs) reach rate constants five to seven orders of magnitude higher. It is likely that other factors, besides $p K_{a}$, are important determinants of Cys reactivity with $\mathrm{H}_{2} \mathrm{O}_{2}$ (see last paragraph of next section). 
Peroxiredoxins contain highly $\mathrm{H}_{2} \mathrm{O}_{2}$-sensitive Cys residues. In fact, even though low $p K_{a}$ values are common among catalytic Cys, fast reactions only happen when substrates are the appropriate for a particular enzyme (21). The reaction of $\mathrm{H}_{2} \mathrm{O}_{2}$ with Prxs is probably one of the best examples to illustrate this concept.

Prxs are a ubiquitous family of proteins, highly expressed in cells, which function not only as main detoxifying enzymes for low intracellular $\mathrm{H}_{2} \mathrm{O}_{2}$ concentrations (28-30), but also as mediators of $\mathrm{H}_{2} \mathrm{O}_{2}$ signaling in eukaryotes (11). Differently than in other types of peroxidases for which substrate-metal binding is required (i.e. heme peroxidases), Prxs use a $\mathrm{S}_{\mathrm{N}} 2$-type mechanism where a thiolate reduces, with high order rates $\left(\sim 10^{7} \mathrm{M}^{-1} \mathrm{~s}^{-1}\right)$ and high specificity peroxide substrates. Thus, the catalytic cycle starts with the thiolate from the 'peroxidatic' Cys in the active site of the Prx attacking on the peroxide substrate, resulting in the peroxide reduced to the corresponding alcohol and the thiol oxidized to a SOH form. Then, in a resolution step, a free resolving $\mathrm{SH}$, either present in the same or in another subunit of the Prx, attacks the SOH to form a disulfide and release water. To complete the cycle, usually a Trx-like protein or domain recycles the formed disulfide (31). In some families of Prxs, in competition with the resolution step, there is an over-oxidation reaction, in which the $\mathrm{SOH}$ can react with more molecules of $\mathrm{H}_{2} \mathrm{O}_{2}$ to form $-\mathrm{SO}_{2} \mathrm{H}$ or $-\mathrm{SO}_{3} \mathrm{H}$, which render the enzyme inactive. The hyper-oxidized $-\mathrm{SO}_{2} \mathrm{H}$ form in these Prxs can be recycled to $\mathrm{SOH}$ at the expense of ATP consumption (10-12).

The $p K_{a}$ of the thiol in the 'peroxidatic' Cys at the active site is stabilized to values below 7 due to hydrogen-bonding interactions (32). However, this low $p K_{a}$ can only explain rate constant values about $20 \mathrm{M}^{-1} \mathrm{~s}^{-1}$, leaving unexplained rate enhancements of 5 to 7 orders of magnitude. Hall and colleagues (32) proposed a model for the conformation of the activesite at the transition state, based on all known structures of Prx-substrate complexes up to 
2011, which could explain the high catalytic rates of Prxs towards their substrates. Thus, they showed how the Prx active-site is perfectly organized to stabilize the transition state. The latter would have a partial bond formed between the sulfur atom and one of the oxygens of the peroxide, and a partial bond broken between $\mathrm{O}-\mathrm{O}$ in a linear transition state. FerrerSueta group (21) later proposed a complementary mechanism to the previous one, in which they suggested that as $\mathrm{H}_{2} \mathrm{O}_{2}$ approaches to the active site, there is a shift of the hydrogen bonds from the thiolate to the substrate, increasing in this way on the one hand the nucleophilicity of the thiolate, facilitating therefore its attack on the distal oxygen, and on the other hand a better leaving group due to a better oxygen stabilization. Hence, for highly efficient catalysis, as important as the activation of the nucleophile (the Cys thiolate) are the stabilization of the transition state and the formation of a good leaving group.

Primary Cys-containing sensors of $\mathrm{H}_{2} \mathrm{O}_{2}$ reactivity. Considering a kinetic model of $\mathrm{H}_{2} \mathrm{O}_{2}-$ mediated thiol oxidation, Prxs and GPxs have been proposed to be the only proteins with Cys likely to be direct targets, to become fully oxidized and to initiate signaling cascades in response to $\mathrm{H}_{2} \mathrm{O}_{2}$ (33). Thus, the thiol groups of Prxs and GPxs are highly reactive to $\mathrm{H}_{2} \mathrm{O}_{2}$ and display high abundance (up to $1 \%$ of total protein in cells) (34). Thiol oxidation in other proteins with less reactive Cys (such as PTPs or GAPDH) is more likely to occur through an indirect mechanism, so that they would have to be selectively oxidized by a 'true sensor' in a second reaction (i.e. indirect oxidation via oxidized Prx of GPx). Only in the case of Prxs and GPxs being fully oxidized, and depending on their reactivity and abundance, would other less reactive thiols be direct targets of the oxidant $(18,21,33,35)$.

A classical example of this biological setting, with a Prx transferring the $\mathrm{H}_{2} \mathrm{O}_{2-}$ dependent signal to a second effector molecule, is the Tpx1-Pap1 redox relay in Schizosaccharomyces pombe. As will be fully described below (see section ' $\mathrm{H}_{2} \mathrm{O}_{2}$-activated 
transcription factors ${ }^{6}$ ), the 2-Cys Trx-dependent Prx Tpx1 acts both as a sensor and as a primary scavenger of the endogenously generated $\mathrm{H}_{2} \mathrm{O}_{2}$. Thus, under physiological conditions, Tpx 1 performs its catalytic cycle detoxifying the $\mathrm{H}_{2} \mathrm{O}_{2}$ concentrations generated during the aerobic growth of the cell (36). However, this Prx has an additional role, upon conditions of oxidative stress (extracellular $\mathrm{H}_{2} \mathrm{O}_{2}$ concentrations around $0.2 \mathrm{mM}$ ), it is able to oxidize a different substrate other than Trx, its naturally reducing system (37). Thus, upon $0.2 \mathrm{mM} \mathrm{H}_{2} \mathrm{O}_{2}$, Tpx1 becomes oxidized forming a disulfide bond with another subunit of Tpx1 and then, by a mechanism still not fully understood, transfers the redox signal to the AP-1 like transcription factor Pap1 $(38,39)$. Once Pap1 is oxidized, it accumulates in the nucleus and triggers an antioxidant program of gene expression. This is an example of how kinetics governs Cys reactivity. Thus, the true sensor of the pathway, Tpx1, specifically transmits the signal to the secondary sensor of the pathway, the transcription factor Pap1. Importantly, Cys residues on Pap1 are not able to directly react with $\mathrm{H}_{2} \mathrm{O}_{2}$, as Pap1 can only be oxidized in the presence of Tpx1, no matter the concentration of the oxidant used.

\section{SOURCES OF REVERSIBLY OXIDIZED THIOLS REDUCTION: TRX AND GSH/GRX SYSTEMS}

We have already discussed how kinetics of thiol oxidation in some proteins allows $\mathrm{H}_{2} \mathrm{O}_{2}$ to act as a second messenger. But, for cellular signaling, as important as differential kinetics of thiol oxidation is the recycling of the same oxidized proteins. Thus, the recycling of sensors has to be fast, but at the same time slow enough to allow them to perform their function prior to their inactivation. Moreover, thiol to disulfide switches not only happen as a consequence of cellular responses to oxidative stress, other proteins with reactive Cys undergo oxidations as part of their catalytic cycles, or as a consequence of changes in the overall thiol-disulfide 
redox balance (40). Thus, to cope with the need of thiol redox control, cells are provided with two major systems meant to control the thiol-disulfide status, the Trx and the GSH/Grx systems.

Trxs and Grxs belong to a group of enzymes that catalyze thiol-disulfide exchange reactions, which in general share a common structural motif known as the Trx fold (41). The conserved Trx fold can be found in a variety of functionally different proteins such as thioldisulfide oxidoreductases, protein disulfide isomerases, disulfide oxidases, glutathione-Stransferases or thiol dependent peroxidases (42). Structurally, it consists of a central four stranded $\beta$-sheet surrounded by three $\alpha$-helices. Hallmarks of the Trx fold in thiol-disulfide oxidoreductases are a cis-proline residue located before the third $\beta$-sheet and the CXXC or CXXS active site motif located on the loop connecting $\beta$-sheet one and $\alpha$-helix one (43-45). The nature of the two amino acids between the redox active Cys determines the standard redox potential of the proteins containing the Trx motif, explaining their different roles as oxidases, reductases or isomerases (46). Thus, Trxs (with a CGPC motif) which are strongly reducing enzymes, have standard redox potentials ranging from -260 to $-285 \mathrm{mV}$ (47), Grxs (with a CPTC motif) are less reducing with standard redox potentials ranging from -198 to $233 \mathrm{mV}(48)$, and periplasmic DsbAs (with a CPHC motif), which are thiol oxidases in the protein folding process, have standard redox potentials ranging from $-90 \mathrm{mV}$ to $-110 \mathrm{mV}$ (46, $49,50)$.

Trxs and Grxs are thiol-disulfide oxidoreductases. Trx was first discovered in 1964 as an electron donor for $E$. coli ribonucleotide reductase (RNR), an enzyme required for DNA synthesis (51). Grx was later discovered as an alternative electron donor for the same enzyme in E. coli mutants lacking Trx (52). From then onwards, it became clear that these oxidoreductases regulate a wide number of processes in eukaryotic and prokaryotic organisms, apart from DNA repair and synthesis, including antioxidant defense and redox 
regulation, sulfur metabolism or apoptosis, by mediating the transfer of electrons to enzymes including Prxs, GPxs, methionine sulfoxide reductases, phosphoadenylyl sulfate (PAPS) reductase or RNR $(50,53)$.

The reaction catalyzed by these oxidoreductases proceeds by $\mathrm{S}_{\mathrm{N}} 2$ type mechanism, in which the electrons coming from Trx or Grx are transferred to a substrate protein. The solvent exposed thiolate of the $\mathrm{N}$-terminal Cys of the CXXC motif, with low $p K_{a}$, attacks on a disulfide in the substrate protein to form an intermolecular mixed disulfide. Upon formation of the mixed disulfide complex, the $p K_{a}$ of the C-terminal Cys of the CXXC motif drops yielding a thiolate, which is then able to break the mixed disulfide with the target protein and generating both reduced target protein and oxidized $\operatorname{Trx}$ or $\operatorname{Grx}(54,55)$. To keep its biological activity, the disulfide formed in the oxidoreductase has to be reduced. In the case of Trx, this process is driven by $\operatorname{Trx}$ reductase $(\operatorname{TrxR})(51,56)$, which shuttles electrons from NADPH to Trx. Trx, together with TrxR and NADPH constitute the Trx system (Figure 2A). In the case of Grx, recycling is done by one molecule of GSH, leading to a mixed disulfide between GSH and the N-terminal active site Cys of the Grx. This mixed disulfide is then reduced by a second GSH molecule (dithiol mechanism, Figure 2B upper panel). Disulfides between GSH and proteins or low molecular weight compounds can be reduced in a different way, which only requires the Grx N-terminal Cys (monothiol mechanism, Figure 2B, lower panel). In this case, the non-GSH molecule is the best leaving group, while GSH forms a mixed disulfide with the N-terminal thiol, which is then reduced by a second molecule of GSH. In both cases, oxidized GSH is formed (GSSG), and this species is then reduced by glutathione reductase (GSHR) at the expense of NADPH (57). Grx together with GSH, GSHR and NADPH constitute the GSH/Grx system. 
Functional roles of the Trx and GSH/Grx systems. Trx and GSH/Grx systems are key mediators of electron flow. These are thermodynamically linked by the ultimate electron donor inside the cell, NADPH (with a redox potential of $-315 \mathrm{mV}$ ) (58). Electrons are therefore transferred from NADPH to final substrates through gradients in redox potentials. But, why is it necessary to have two different systems acting in thiol-redox control? Are these systems redundant? Many studies have been performed in this regard with different outcomes depending on the studied species.

In E. coli, the two systems seem to be largely redundant, only mutants lacking enzymes of both pathways are not viable. Thus, double mutants lacking Trx and Grx or Trx and GSH ( $\Delta \operatorname{tr} x A \Delta g r x A$ or $\Delta \operatorname{trx} A \Delta g s h A)$ are unviable due to accumulation of PAPS, a toxic metabolite from the sulfate assimilation pathway, suggesting that both TrxA and GrxA are required for PAPS reduction (59). Likewise, E. coli lacking Trx, Grx, GSH and GSHR $(\Delta \operatorname{trx} A \Delta \operatorname{trx} C \Delta g r x A, \Delta \operatorname{trx} B \Delta g \operatorname{sh} A, \Delta \operatorname{trx} B \Delta g o r, \Delta \operatorname{trx} A \Delta \operatorname{trx} C \Delta g s h A)$ are aerobically unviable as a consequence of defective RNR type I (NrdAB, class Ia) reduction (60), suggesting that TrxA, TrxC, and GrxA are alternative electron donors for this RNR (61-63). Importantly, these systems do not seem to have a major role in the detoxification of $\mathrm{H}_{2} \mathrm{O}_{2}$ in this organism. Thus, E. coli only carries a Trx-dependent GPx homologue (BtuE) (64), and it uses the Prx AhpC as the major peroxide-scavenging enzyme (28). The particularity of this enzyme is that it uses its own NADH- (and occasionally NADPH-) dependent reductase, AhpF, a protein harboring a TrxR-like core of two domains connected to a third N-terminal domain composed of two Trx-like domains (58). These systems are important however to reduce the highly $\mathrm{H}_{2} \mathrm{O}_{2}$-sensitive antioxidant transcription factor OxyR, at least in vitro, although Grx1 is likely to be the in vivo reductant (65-67).

In contrast, the Trx and GSH/Grx systems are not fully redundant in eukaryotes. Thus, in yeast, the Trx system is the main electron donor for enzymes including RNR, PAPS 
reductase, methionine sulfoxide reducatases, Prxs, and GPxs. Accordingly, S. cerevisiae mutants lacking both cytoplasmic Trxs ( $\Delta \operatorname{trx} 1 \Delta t r x 2)$ have an extended S-phase, a lower pool of deoxyribonucleotides, and an increased fraction of oxidized RNR. However, these mutants are still viable, suggesting a role for the GSH pathway in (inefficient) RNR reduction. Hence a quadruple mutant lacking both cytoplasmic Trxs and Grxs is not viable

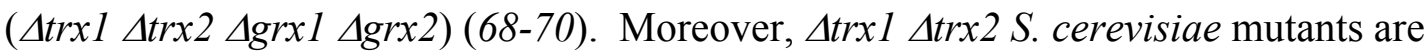
auxotrophic for sulfur amino acids (69), unless these are grown in a low oxygen atmosphere or in the absence of functional mitochondria, in which case the GSH/Grx pathway can inefficiently reduce PAPS reductase (68). In addition, the Trx system has a major role in $\mathrm{H}_{2} \mathrm{O}_{2}$ detoxification in yeast by acting as an electron donor for the two different families of peroxidases that are present in this organism, the Prxs Tsa1, Tsa2, Ahp1, nTpx, and mTpx (71-73) and the GPx-like proteins Gpx1, Gpx2, and Gpx3 $(74,75)$. Similarly, in the fission yeast $S$. pombe there are three Trx-dependent peroxidases, the Prxs Tpx1, Pmp20 and BCP (76), and one member of the GPx family, Gpx1 (77). Tpx1 is the main detoxifier of the $\mathrm{H}_{2} \mathrm{O}_{2}$ endogenously generated during the aerobic growth of the cell, hence $S$. pombe cells lacking Tpx 1 are only viable on plates when grown under an anaerobic atmosphere $(36,38)$. Tpx1 is a major substrate for thioredoxins (78), and S. pombe cells lacking both cytoplasmic Trxs (Trx1 and Trx3) display constitutively oxidized Tpx1 (37), although a combination of three gene deletions ( $\Delta \operatorname{trx} 1 \Delta \operatorname{trx} 3 \Delta g r x 1)$ is needed to render these cells unviable aerobically, suggesting a secondary role for the GSH/Grx system in Tpx1 reduction. Moreover, the transcription factors $S c$ Yap1 and its $S$. pombe homologous Pap1, both triggering an antioxidant program upon $\mathrm{H}_{2} \mathrm{O}_{2}$ - and peroxidase-mediated thiol oxidation (see below, section ' $\mathrm{H}_{2} \mathrm{O}_{2}$-activated transcription factors') are constitutively active in yeast mutants lacking TrxR $(79,80)$. 
According to the above depicted role for the Trx system in the yeast thiol-redox control, it would seem that the GSH/Grx system does not have a significant function in these organisms. However, GSH is an essential metabolite in yeast. Thus, yeast cells lacking $\gamma$ glutamylCys synthetase (Gsh1), the enzyme catalyzing the rate limiting step on GSH biosynthesis, are aerobically and anaerobically not viable, only growing if GSH is exogenously provided to the media (81). Since these cells are anaerobically not viable, and mutants lacking both cytoplasmic Grxs ( $\Delta g r x 1 \Delta g r x 2)$ are viable, it seems that GSH essentiality is neither due to a ROS-protective function nor to an oxidoreductase activity of the metabolite. Then, what is the molecular cause of this lethality? Toledano and coworkers determined that GSH cellular depletion provoke major alterations in iron metabolism, without causing major repercussions in thiol-redox control (82). Only in the case of an excessive load of GSH the oxidative protein folding and secretion pathways would be blocked. The conclusion from their work is that GSH is not required for cellular thiolredox control unless there is a failure of the Trx system, in which case GSH would act as a back-up of the Trx system $(58,82,83)$. The essential role of GSH in budding yeast is related to its participation in iron-sulfur cluster assembly (82).

Electron flow control by Trx and GSH/Grx systems. The importance of these systems as electron flow pathways was demonstrated 20 years ago by Beckwith and colleagues (84). They designed a disulfide reporter system taking advantage of the periplasmic enzyme alkaline phosphatase (AP) in E. coli, which became active when folded by intra-molecular disulfide bond formation. If expressed in the cytoplasm, upon removal of its signal sequence, the protein was not properly folded due to lack of oxidation and remained inactive. However, in a mutational screening, this group found that AP activity was restored in the cytoplasm of cells lacking TrxR (TrxB in E. coli) (84). Later, they showed that deletion of 
the two E. coli cytoplasmic Trxs, TrxA and TrxC, completely eliminated the AP activity restored by TrxB (85). These results suggested that lack of TrxR promoted the formation of disulfide bonds in proteins (in this particular case, formation of an AP intra-molecular disulfide) due to accumulation of oxidized Trxs. As a consequence of electron flow disruption upstream of Trx in the Trx system, the activity of this protein is shifted from a reducing catalyst into an oxidant one. In accordance with these results, we have recently investigated the role of Trx and TrxR in general thiol homeostasis in the fission yeast $S$. pombe (86). We found that the levels of basal thiol oxidation in cells lacking Trx1 (the main cytoplasmic Trx in this organism) are very similar to those of a wild-type strain. Only few Cys residues in specific proteins are clearly reversibly oxidized in $\Delta \operatorname{trx} 1$ cells (86). These proteins with oxidized Cys belong to classical Trx substrates, those proteins that switch the redox status of some of their Cys in their catalytic cycles, and require electrons from Trx to return to their initial reduced state (Tpx1, Gpx1, PAPS reductase, and the methionine sulfoxide reductases Mxr1 and Mxr2). The absence of massive thiol oxidation in this strain background points to Trx1 being dispensable to maintain general cytoplasmic thiols reduced. However, we observed massive thiol oxidation in cells lacking the only $S$. pombe TrxR ( $\Delta t r r 1)(86)$. Proteins with oxidized Cys in this background belonged to many different functional categories, a scenario more likely emulating a disulfide stress, defined as a situation involving non-native disulfide bond formation, between or within proteins, which can lead to toxicity due to general protein misfolding. Importantly, thiol oxidation was significantly decreased upon removal of the two $S$. pombe cytoplasmic Trxs (Trx1 and Trx3), and their major substrate, the Prx Tpx1. Our results suggest that the absence of the Trx system does not trigger general thiol oxidation per se, but elimination of its reductase does so through accumulation of oxidized Trxs and Tpx1. These studies point to Trxs as main keepers of reduced solvent-exposed Cys, but only when there is an appropriate reducing 
environment, which in this case means presence of TrxR and reduced cofactor NADPH. Furthermore, these Trxs may participate in general thiol reduction after oxidative stress, but are not required to maintain exposed Cys residues reduced during normal aerobic growth.

\section{$\mathrm{H}_{2} \mathrm{O}_{2}$-ACTIVATED TRANSCRIPTION FACTORS}

Different signaling cascades in both prokaryotic and eukaryotic cells are activated when the intracellular concentrations of $\mathrm{H}_{2} \mathrm{O}_{2}$ rise above certain thresholds, with the role of triggering antioxidant programs, mainly at the transcriptional level.

As mentioned in the first section of this Review, intracellular signaling is mostly mediated by $\mathrm{H}_{2} \mathrm{O}_{2}$, an oxidant less reactive than other ROS. The mild reactivity of $\mathrm{H}_{2} \mathrm{O}_{2}$ with target proteins must, therefore, be compatible with the nanomolar range of concentrations of this oxidant in the cell. On the other hand, targets should have a unique reactivity to outcompete interactions of $\mathrm{H}_{2} \mathrm{O}_{2}$ with other targets, in order to account for the specificity required in signaling (33). In addition to specificity, other signaling criteria to meet are fast kinetics and reversibility. Oxidation and reduction of thiol groups of protein Cys is probably the main mechanism by which $\mathrm{H}_{2} \mathrm{O}_{2}$ integrate into cellular signaling pathways. A proposed mechanism relies on the presence of very reactive thiol proteins, called sensor proteins, that once oxidized would facilitate the oxidation of other target proteins through selective protein-protein interactions and thiol exchange. As fully described in previous sections of this review, Prxs and GPxs, due to their low $p K_{a}$, their constant rates and their ubiquity and abundance, would be the only cellular thiol proteins with enough reactivity for being direct targets of $\mathrm{H}_{2} \mathrm{O}_{2}$, and therefore behaving as sensor proteins acting in

signaling cascades (33). However, few exceptions to this rule have been described in some cell types. 
In the next paragraphs we will discuss the reactivity of prokaryotic and eukaryotic sensors and their transducer proteins as well as their role in signaling cascades. Although all the sensor proteins discussed below may be modified by different oxidizing chemicals, we will keep our focus on $\mathrm{H}_{2} \mathrm{O}_{2}$ mediated signaling. We do not intend to provide a full list of proteins activated by $\mathrm{H}_{2} \mathrm{O}_{2}$ to induce transcriptional stress programs, but rather to summarize the results regarding four representative examples: OxyR in E. coli, Yap1 and Pap1 in budding and fission yeast, and Nrf2 in animal cells.

\section{OxyR, activator of the $\mathbf{H}_{2} \mathbf{O}_{2}$-dependent response in $\boldsymbol{E}$. coli. OxyR is a $34 \mathrm{kDa}$}

protein member of the LysR family of transcription activators (87) generally found in Gram-negative bacteria, but that also occurs in a few Gram-positive bacteria $(88,89)$. OxyR is considered as a classical peroxide receptor because it is activated by low $\mathrm{H}_{2} \mathrm{O}_{2}$ levels just above cellular physiological concentration (it is activated at concentrations over $20 \mathrm{nM}$ ) and below the threshold toxic level estimated at $>1 \mathrm{mM}(65)$. These small increments in peroxide concentrations are sensed by a fast reaction of the oxidant with Cys199 of the protein (reaction rate $1.1 \times 10^{5} \mathrm{M}^{-1} \mathrm{~s}^{-1}$ ) (90). As will be fully described below, OxyR performs both sensing and transcriptional regulatory functions.

Like other regulators of the LysR family, it contains a conserved N-terminal helixturn-helix DNA binding domain, a central recognition and response domain which senses the regulatory signal, $\mathrm{H}_{2} \mathrm{O}_{2}$, and a $\mathrm{C}$-terminal domain that functions in multimerization and transcriptional activation $(87,91-94)$.

OxyR functions primarily as a global regulator of the peroxide stress response that keeps intracellular $\mathrm{H}_{2} \mathrm{O}_{2}$ levels below toxic levels (95), but also plays a role in the cellular response to thiol depletion (65) and to nitrosative stress, the latter under anaerobic nitrate respiration growth conditions (96). 
The OxyR regulon of Escherichia coli regulated by peroxide stress is comprised by over 40 genes most of them being positively regulated, and only a few are repressed by OxyR (97). The genes included in the OxyR regulon are involved in $\mathrm{H}_{2} \mathrm{O}_{2}$ detoxification (katE, ahpCF), heme biosynthesis (hemH), reductant supply (grxA, gor, trx C), thiol-disulfide isomerization $(d s b G)$, Fe-S center repair (sufA-E, sufS), iron binding (yaaA), repression of iron import systems (fur), and manganese import (98-100).

Homotetrameric OxyR is bound to promoter-operator regions of target genes in uninduced conditions (Figure 3A). Direct oxidation of Cys residues in OxyR by $\mathrm{H}_{2} \mathrm{O}_{2}$ changes the conformation of the tetramer which, in turn, increases the affinity of OxyR for its DNA binding sites (101-103), and triggers the activation of OxyR bound promoters. The activation of OxyR by $\mathrm{H}_{2} \mathrm{O}_{2}$ is a transient process since oxidized OxyR is slowly reduced via glutaredoxin 1 (Grx1) using electrons supplied by reduced GSH (65-67).

Two basic models have been proposed to describe the molecular mechanism of oxidant sensing by OxyR. According to the first "conformational switch" model, OxyR directly reacts with $\mathrm{H}_{2} \mathrm{O}_{2}$ through a unique Cys residue (Cys199) which, under basal conditions, is stabilized in the thiolate form by a conserved arginine, among other amino acids (104). When intracellular $\mathrm{H}_{2} \mathrm{O}_{2}$ levels reach $100 \mathrm{nM}$, Cys199 is oxidized to $\mathrm{SOH}$. The reaction rate for SOH formation is very rapid $\left(\sim 10^{5}-10^{7} \mathrm{M}^{-1} \mathrm{~s}^{-1}\right.$, depending on the method), which reflects the high $\mathrm{H}_{2} \mathrm{O}_{2}$ reactivity of Cys199 (105). Cys199-SOH rapidly reacts with Cys208 SH to form an intramolecular disulfide bond $(67,104)$. Cys 199 and Cys208 are far apart one from each other, $\sim 17-18 \AA$, but also separated by a rigid $\alpha$-helix $(104,106,107)$. Therefore, in order to form a disulfide bond, there has to be a dramatic conformational change that occurs with a rate constant of $\sim 9.7 \mathrm{~s}^{-1}(90)$. The driving force for this conformational switch seems to be the flipping-out of the Cys199-SOH from the hydrophobic inter-domain pocket that can no longer fit the $\mathrm{SOH}$. The ejection of the 
oxidized Cys renders the region more flexible and the chances of meeting Cys208 in another flexible loop are increased. When these two Cys meet, they form the disulfide bond resulting in a second structural rearrangement in the regulatory domain (amino acids 80-305) (108) that finally alters the associations between the subunits within the tetramer, leading to altered DNA binding properties and allowing transcription activation. But, what about the reverse step of OxyR inactivation by reduction of the disulfide bond? Studies employing circular dichroism did not reveal differences between reduced and oxidized OxyR (90). However, fluorescence spectroscopy studies analyzing the fluorescence of OxyR Trp175 revealed that the oxidized state is destabilized by $\sim 3 \mathrm{kcal} / \mathrm{mol}$ compared to reduced OxyR. Thus, local destabilization of the oxidized form appears to mediate the reverse conformation switch once the disulfide is reduced by Grx1 (90).

The second model to describe OxyR activation by $\mathrm{H}_{2} \mathrm{O}_{2}$, named "molecular code" model, suggests that oxidation of Cys199 alone is sufficient to activate OxyR in the absence of disulfide bond formation (109). Different forms of Cys199 oxidation resulting from different redox agents (sulfenylated Cys199-SOH, S-nitrosylated Cys199-SNO, and Sglutathionylated Cys199-SSG), appear to generate different outputs in OxyR while modifying the same Cys. This model was first based primarily on in vitro studies of transcription activation by the different forms of oxidized OxyR and on circular dichroism analysis of the different OxyR-DNA complexes $(109,110)$. This model was later reinforced by the observation that OxyR Cys 199 thiol esterification resulted in the activation of target genes both in vitro and in vivo (111). Interestingly, the set of genes activated by OxyR nitrosylation was distinct from those activated in response to $\mathrm{H}_{2} \mathrm{O}_{2}$. Only Cys199, one of the six Cys residues in OxyR, was nitrosylated, indicating that this modification is highly specific. It would be therefore interesting to determine the structural changes induced by Snitrosylation and to explain how these changes affect its specific activity. Very recently, 
Seth and colleagues demonstrated that Cys199 of OxyR was nitrosylated in vivo in response to endogenous nitrosative stress in a way independent of nitric oxide synthases or $\mathrm{O}_{2}(96)$.

A second structural class of OxyR proteins, with only one Cys, has been identified in Deinococcus radiodurans $(112,113)$. DrOxyR and $\mathrm{DrOxyR}_{2}$ are the two novel proteins found in this organism and each contains only one Cys roughly corresponding to Cys208 in the E. coli protein. They also contain conserved residues that have been implicated in DNA binding, activation, and multimerization. However, residues in the E. coli protein that are predicted to play a role in $\mathrm{SOH}$ formation at Cys199 and subsequent disulfide formation with Cys208 are absent in this protein. In vitro chemical modification studies have shown that $\mathrm{H}_{2} \mathrm{O}_{2}$ dependent activation of $\mathrm{DrOxyR}$ involves the formation of a $\mathrm{Cys} \mathrm{SOH}$ at the essential sensing Cys (112). Despite the differences in the sensing mechanism that necessarily exist between 1-Cys and 2-Cys OxyR proteins, the truth is that DrOxyR is able to complement an E. coli OxyR mutant, indicating, at least, functional similarity.

Yap1 in Saccharomyces cerevisiae. Yap1 is a bZIP DNA binding protein member of the eukaryote AP-1 family of transcription factors that includes mammalian transcription factors such as c-Jun (114). It is an essential regulator of the $\mathrm{H}_{2} \mathrm{O}_{2}$ adaptive response $(115,116)$ and regulates the expression of genes of the $\mathrm{H}_{2} \mathrm{O}_{2}$ regulon coding for most cellular antioxidants (Trx2) and enzymes of the glutathione and pentose phosphate pathway $(72,116,117)$. Yap1 is a 650 amino acid protein structured in three domains. The N-terminal domain contains a nuclear localization signal (NLS) and the basic-leucine zipper (bZIP) DNA interacting domain. The central and C-terminal domains contain three Cys each and are called Cys-rich domains (nCRD and cCRD, respectively). The cCRD has also embedded a non-canonical nuclear export signal (NES) that interacts with Crm1/Xpo1 and that in basal conditions restricts Yap1 to the cytoplasm (Figure 3B). 
Yap1 is activated upon exposure to different oxidants like peroxides or thiolmodifying drugs such as diamide (110). However the mechanism of Yap1 activation is different depending on the oxidant. In the specific case of activation by $\mathrm{H}_{2} \mathrm{O}_{2}$, oxidation of a subset of Yap1 Cys residues leading to at least three different disulfide bonds results in a conformational change that masks the Yap1 NES and therefore Yap1 accumulates at the nucleus where it binds to target genes and activates their transcription (118-120). After a certain time, Yap1 is reduced by thioredoxins $\operatorname{Trx} 1$ and $\operatorname{Trx} 2$ and the protein returns to its main cytosolic localization (121).

Yap1 is activated by mild levels of $\mathrm{H}_{2} \mathrm{O}_{2}$ ranging from 0.1 to $0.8 \mathrm{mM} \mathrm{H}_{2} \mathrm{O}_{2}$ and Yap1 oxidation and nuclear accumulation is observed within minutes of $\mathrm{H}_{2} \mathrm{O}_{2}$ treatment (121). Direct oxidation of Yap1 by $\mathrm{H}_{2} \mathrm{O}_{2}$ does not occur. Instead, $\mathrm{H}_{2} \mathrm{O}_{2}$ oxidizes the GPx-like protein Gpx3/Orp1 that, in turn, oxidizes Yap1 $(75,122)$. Still, the in vivo activation of Yap1 by Orp1 requires a third partner, Ybp1. The role of $\mathrm{Ybp} 1$ is not yet fully understood, but it may participate in either holding Gpx3 and Yap1 together or stabilizing Yap1 (123-125).

The mechanistic details of Yap1 activation, schematically summarized in Figure 3B, have been addressed by different groups using both in vivo and in vitro reconstitution assays with different versions of Yap1 Cys mutants $(75,122,126,127)$. Thus, even though the particular Cys residues in Yap1 and Orp1 involved in the activation process have been identified, the precise sequential disulfide bond rearrangements that take place in the Yap1 protein are not yet fully understood. In basal conditions, most of the population of Yap1 is cytosolic and interacts with the Ybp1 protein through a Yap1 region encompassing residues from 379 to 650 , that includes the Yap1 transactivation domain and the cCRD (123), and also with Orp1 (75). Upon $\mathrm{H}_{2} \mathrm{O}_{2}$ treatment, Orp1 Cys36 is directly oxidized to $\mathrm{SOH}$ and, then, this Cys36-SOH reacts with Yap1 Cys301 to form an Orp1-Yap1 disulfide bond. This transient Yap1-Orp1 intermolecular disulfide linkage is then isomerized to the intramolecular 
C301-SS-C598 disulfide of Yap1, releasing reduced Orp1. The interaction of Orp1 with Yap1 under basal conditions without any intervening covalent bond may explain why Orp1 Cys36-SOH reacts more readily with Yap1 Cys598-SH than with Orp1 resolving Cys82, as Yap1 Cys598 may be closer to Orp1 Cys36 than Orp1 Cys82. The high reactivity of Orp1 Cys36 is explained by its low $p K_{a}(5.1)$ and amino acid environment (122). Mass spectrometry and NMR studies of oxidized Yap1 revealed the existence of two disulfide bonds, one engaging the already described Cys301 and Cys598 and a second one between Cys310 and Cys629 $(126,128)$. These two disulfide bonds are necessary to bring together the nCRD and the cCRD domains masking the NES sequence. However, they are not sufficient to stabilize the interaction between the two domains, and other amino acids like Phe302 and Met306 may be necessary. Another study using an in vitro reconstituted system containing Orp1, Yap1, the thioredoxin system and NADPH, showed that oxidation of all six Yap1 Cys residues generates four oxidized forms of Yap1 of increased thermodynamic stability (127). The first of these disulfide bonds occurs within $15 \mathrm{sec}$ upon exposure to $\mathrm{H}_{2} \mathrm{O}_{2}$ and is an intra nCRD bond between Cys310 and Cys315. Then, in the next five minutes, a disulfide bond linking Cys301 (nCRD) and Cys598 (cCRD) is formed. A third step is the formation of another bond between the nCRD and cCRD domains involving Cys310 and Cys629. The authors suggest that the first intra nCRD bond may help the formation of the latter disulfide link. Finally, as the levels of reduced Trx start to increase, because the levels of $\mathrm{H}_{2} \mathrm{O}_{2}$ are decreased, another disulfide between Cys 315 and Cys620 could be formed. The subsequent generation of three disulfides linking nCRD and cCRD would contribute to an efficient and prolonged response $(127,129)$. In this sense, it has been shown that the proper folding of Yap1 in the presence of $\mathrm{H}_{2} \mathrm{O}_{2}$ is not only required for nuclear accumulation but also for recruitment of Rox3, a mediator component, to the $T R X 2$, but not to the GSH1, promoter. The generation and function of the nCRD intradomain 
disulfide is not understood, either. Finally, another important question that remains unanswered is how the disulfide bonded Cys residues that are separated by a $\sim 300$ amino acid domain can be brought together in such a rapid and precise manner.

It is also worth mentioning that some budding yeast strain backgrounds display a different setting regarding the Yap1 redox relay. Thus, in some specific strains the Prx Tsa1 is also required for Yap1 activation. Tsa1 was originally identified in a screen for mutants that prevented Yap1 activation (130). However, this requirement is only observed in the absence of $Y B P 1$, which occurs in those strain backgrounds $(123,131)$, and the oxidation of Yap1 is much weaker than in cells with active $\mathrm{Ybp} 1$ where $\mathrm{H}_{2} \mathrm{O}_{2}$ oxidation is catalyzed by Orp1. In the absence of Ybp1, Yap1 interaction with Orp1 may not be favored and because the steady state protein level of Tsa1 is 45 times that of Orp1, it may catalyze $\mathrm{H}_{2} \mathrm{O}_{2}$ oxidation of Yap1. In fact, in vitro reconstitution assays with Tsa1, Yap1, the thioredoxin system and NADPH showed that Tsa1 Cys48 could generate an intermolecular disulfide bond with Yap1, in an analogous way to Orp1, followed by an exchange reaction producing a Yap1 intramolecular bond. As opposed to Orp1, Tsa1 resolving Cys171 is required for Yap1 activation. This can be explained by the fact that Tsa1 forms a homodimer linking Cys48 of one monomer with the resolving Cys 171 of the other monomer, leaving the other Cys48 of the dimer in the thiol form. The SOH form of Tsal Cys48 of the dimer would then catalyze Yap1 oxidation by forming an intramolecular disulfide bond (131).

Schizosaccharomyces pombe Pap1. The Pap1 transcription factor is the homolog of budding yeast Yap1 (132-134). It also responds to moderate levels of peroxides (around 0.2 $\mathrm{mM}$ extracellular $\mathrm{H}_{2} \mathrm{O}_{2}$ ) by rapidly adopting a conformation that blocks its nuclear export and allows its transient accumulation in the nucleus (80) Similarly to Yap1, Pap1 may be modified by other oxidants than $\mathrm{H}_{2} \mathrm{O}_{2}$, but, again, the activation and Cys residues involved 
differ from those observed with $\mathrm{H}_{2} \mathrm{O}_{2}$ (135) Despite these similarities between Yap1 and Pap1, the two proteins differ in the sensor protein that catalyzes their oxidation, Orp1 (a GPx-like protein) for Yap1 and Tpx1 (a Prx) for Pap1. The different features of these two peroxidases, discussed below, is the basis for the narrow range of $\mathrm{H}_{2} \mathrm{O}_{2}$ levels to which Pap1 responds and explains why S. pombe has evolved two different, although overlapping, $\mathrm{H}_{2} \mathrm{O}_{2}$ signaling pathways, an adaptive pathway driven by Pap1, and a survival pathway, activated at high levels of $\mathrm{H}_{2} \mathrm{O}_{2}$, driven by the MAP kinase Sty1 and the Atf1 transcription factor (37, 38,136 ). In response to moderate doses of $\mathrm{H}_{2} \mathrm{O}_{2}$ (extracellular 0.07-0.2 mM), Pap1 upregulates the expression of around 40-80 genes related to both antioxidant defense and multidrug resistance $(133,134,137,138)$. However, as the transcriptional activation of multidrug resistance genes only requires nuclear Pap1 accumulation, the up-regulation of genes involved in the adaptive response to oxidative stress such as $\operatorname{trr} 1, \operatorname{ctt} 1$ or $\operatorname{srx} 1$, requires the nuclear accumulation of oxidized Pap1 containing at least one disulfide bond. Proper oxidation of Pap1 allows full transcription of these genes by interacting with Prr1, the other transcription factor that partners with Pap1 to induce the antioxidant defense (138).

Pap1 contains seven Cys residues clustered in two domains, one at the center of the polypeptide called N-terminal Cys rich domain (nCRD) containing four Cys and the second at the C-terminal domain (cCRD) containing the other three Cys residues. A model for the mechanism of Pap1 activation is shown in Figure 3C. After only 1-5 min upon moderate $\mathrm{H}_{2} \mathrm{O}_{2}$ stress, Pap1 accumulates at the nucleus by a mechanism involving the formation of at least one intramolecular disulfide bond that contributes to the dissociation between Pap1 and the Hba1-Crm 1 nuclear export machinery $(38,80,135,139)$. Early studies using Cys substitutions in the nCRD Cys278 and cCRD Cys 501 showed that nuclear Pap1 accumulation was fully and largely, respectively, prevented in these two mutants (135). Further studies using Cys mutations in the endogenous pap1 locus indicated that Cys278, 
Cys285 and Cys532 were essential to trigger the conformational change observed with nonreducing electrophoresis, to trigger nuclear accumulation and to tolerate peroxides at wildtype levels. We also showed that although Cys501 was required for Pap1 oxidation and for nuclear accumulation, substitution of this Cys did not fully impair transcriptional activation (39). In addition, proteomic analysis of the in vivo Pap1 redox state in basal and induced conditions revealed that all seven Cys residues were reduced in untreated conditions and at least four of them, Cys278, 285, 501 and 532, appeared to be reversibly oxidized after exposure to $\mathrm{H}_{2} \mathrm{O}_{2}(39)$.

It has been established that Tpx1 senses $\mathrm{H}_{2} \mathrm{O}_{2}$ fluctuations and initiates the process of Pap1 oxidation, probably by a thiol disulfide exchange reaction (37). Whereas under physiological conditions Tpx1 performs its catalytic cycle detoxifying the $\mathrm{H}_{2} \mathrm{O}_{2}$ concentrations generated during the aerobic growth of the cell (36) and Trx1 restores the redox state of Tpx1, under conditions that deplete reduced Trx1 and, therefore, the normal aerobic catalytic Tpx 1 becomes saturated, that is, at concentrations of $\sim 0.2 \mathrm{mM}$ extracellular $\mathrm{H}_{2} \mathrm{O}_{2}$, Pap1 becomes the alternative electron donor to reduce Tpx1 (37). We proposed that fully oxidized Tpx1 dimer transfers a disulfide bond between catalytic Cys48 and resolving Cys169 to Pap1. That would explain why the two Cys residues in Tpx1 are required for Pap1 oxidation (37). We have to indicate, however, that an alternative explanation for this Cys169 requirement is that the Tpx1 dimer capable of transferring the redox signal to Pap1 should contain an intra-dimer disulfide between Cys48 of one monomer and Cys169 of the other, with the other Cys48-SOH in the dimer being responsible to engage Pap1 activation. Furthermore, a full Tpx1 cycle could also be required to trigger Pap1 activation, with only a small percentage of Pap1 oxidation occurring at each Tpx1 cycle; this setting should also justify the requirement of both Cys48 and Cys169 in Tpx1. 
The cycle of $\mathrm{H}_{2} \mathrm{O}_{2}$ scavenging by Prxs also explains the narrow range of $\mathrm{H}_{2} \mathrm{O}_{2}$ concentrations able to trigger Pap1 oxidation. Thus, at high concentrations of $\mathrm{H}_{2} \mathrm{O}_{2} \mathrm{Tpx} 1$ is inactivated by hyperoxidation of its catalytic Cys 48 to a $\mathrm{SO}_{2} \mathrm{H}$ form. This form can only be reduced back to a thiol form by the sulfiredoxin Srx1, which expression depends on the activation of the Sty1 pathway, which in turn becomes maximally activated at higher doses of peroxides $(38,136)$. The substrate-dependent inactivation of Tpx1 explains the inhibition of Pap1 activation at high doses of $\mathrm{H}_{2} \mathrm{O}_{2}$. In contrast, activation of Yap1 by the GPx-like Orp1 is not limited to low levels of peroxides.

Gpx1 is another Trx-dependent peroxidase member of the GPx family present in $S$. pombe (77). In the absence of Tpx1, Gpx1 can also initiate Pap1 oxidation and trigger nuclear accumulation and activate transcription of Pap1 dependent genes, but only when massively overexpressed from a plasmid (37). However, this activation only occurs at high concentrations of $\mathrm{H}_{2} \mathrm{O}_{2}(2 \mathrm{mM})$ due to the lower affinity of $\mathrm{Gpx} 1$ for $\mathrm{H}_{2} \mathrm{O}_{2}$.

The transcriptional activation of Pap1 is transient (with a maximum at $15 \mathrm{~min}$ ), although the oxidized form of Pap1 observed in non-reducing gel electrophoresis starts to decline even earlier. The reduction of Pap1 seems to depend on the Trx system. In particular Trx 1 and, to a less extent, Trx3, are responsible for Pap1 reduction; thus, the absence of Trx 1 results in a significant increase of the gene expression program under basal conditions and a sustained transcriptional activation of Pap1 dependent genes after stress imposition (37).

Nrf2/Keap1 in animal cells. As opposed to unicellular organisms, pluricellular organisms use multiple defense mechanisms to ensure protection against the toxic effects of oxidants and electrophiles to which they are exposed. These defense systems may be divided into four categories: (i) phase I enzymes, such as P450 enzymes, that introduce functional groups onto hydrophobic organic molecules; (ii) phase II enzymes, which conjugate the highly 
reactive products of phase I enzymes with hydrophilic groups, such as GSH or UDPglucuronic acid, to facilitate their excretion. This group also includes enzymes like superoxide dismutase, GPx, and catalase, which inactivate reactive oxygen species; (iii) phase III efflux transporters that export toxic metabolites; and (iv) thiol containing molecules such as GSH and Trx, which function to both maintain cellular redox homeostasis and inactivate electrophilic compounds. An additional category of proteins involved in detoxification are ubiquitination enzymes and proteasome subunits that mediate degradation of oxidized proteins (140).

The induction of phase II enzymes requires at least three essential components: (i) antioxidant response elements (ARE) in the promoter regions of these genes, either single or in multiple copies (141); (ii) Nrf2 (nuclear factor-erythroid 2-related factor), the main transcription factor that upon heterodimerization with members of the small Maf family of transcription factors, binds to the ARE and recruits the general transcriptional machinery for expression of ARE-regulated genes (142); and (iii) Keap1, a cytosolic repressor protein that binds to Nrf2, retains it in the cytoplasm, and promotes its proteasomal degradation. The main body of data indicates that transcriptional activity of Nrf2, determined by its level of expression and its distribution between the nucleus and the cytoplasm, depends primarily on Keap1 that acts as the real receptor of electrophilic compounds and oxidants (143). However, the Keap1/Nrf2 system can also be activated by phosphorylation (144) since protein kinase R-like endoplasmic reticulum kinase and protein kinase C phosphorylate Nrf2 directly in vitro and in vivo, resulting in Nrf2 dissociation from Keap1, thus preventing its ubiquitination and degradation.

Keap1 (Kelch-like ECH-associated protein 1) belongs to the superfamily of BTBKelch proteins in metazoan and consists of five distinct domains. The amino terminal region (NTR) is comprised by the first 60 amino acids. Amino acids $61-179$ form the BTB/POZ 
domain (bric-a-brac, tramtrack, broad complex/Poxvirus zinc finger). This domain is evolutionary conserved and usually functions as a protein-protein interaction domain that mediates dimerization. Keap1 is linked through the BTB domain with the scaffold protein Cul3, which, along with ubiquitin ligase Rbx1, constitute the ubiquitin ligase E3 complex $(145,146)$ responsible of Nrf2 ubiquitination. The Keap1 monomers are assembled into a paired complex through the BTB domain and this dimerization is required for binding to Nrf2 (147). The intervening region (IVR) of Keap1, particularly rich in Cys residues (nine Cys among 134 amino acids) encompasses amino-acids 180-314 (143, 148). This is the domain where the highly reactive Cys residues reside. Keap1 binds $\mathrm{Zn}^{2+}$ ions (molar ratio of $1: 1 ; \mathrm{K}_{\mathrm{a}} \sim 10^{11} \mathrm{M}^{-1}$ ) through Cys254, 273, 288, and 293, and some histidine residues which also embedded in the IVR domain (149). It is possible that the binding to $\mathrm{Zn}^{2+}$ of several of these Cys may contribute to their ionization and high reactivity. Actually, the reaction of these Cys with oxidants leads to $\mathrm{Zn}^{2+}$ release and disulfide-bond formation. The double glycine repeat (DGR) or Kelch domain spans amino acids 315-608. It is this domain through which Keap1 binds to Nrf2. The Kelch repeat motif is defined by highly conserved glycine, tyrosine, and tryptophan residues. There are eight Cys residues that are not engaged in signal-mediated disulfide bonds. Finally, amino-acids 609-624 comprise the carboxyterminal domain (CTR). This region ends with a conserved triple CTC repeat reminiscent of the CXXC sequence found in the active site of protein disulfide isomerases. It has been reported that a tripeptide CGC- $\mathrm{NH}_{2}$ possesses disulfide isomerization activity (150), but this activity has not yet been determined for the CTC sequence of Keap1.

The identification of physiologically relevant Cys residues for Keap1 sensing function has resulted elusive for several reasons. First, Keap1 contains 25 (mouse) or 27 (human) Cys, and at least 10 of them are predicted to be highly reactive as they are located in the vicinity of positively charged amino acids which reduce the $p K_{a}$ of thiol groups. Second, 
in vitro studies have been performed to determine the reactivity of Keap1 Cys residues treating recombinant Keap1 with several compounds of very different chemical nature and at a wide range of concentrations, with complicated and sometimes contradictory results. Third, also in vivo studies were performed, using wild-type and Cys-mutants of Keap1, and again a plethora of different chemicals were used, but also many different assays were performed with different readouts (ARE-dependent gene activation, Keap1-Nrf2 binding, Nrf2 ubiquitination and degradation...). Excellent reviews have been published that comprehensively report the available data $(143,151-153)$. However, despite the great diversity of approaches, Cys151 of the BTB domain and Cys288 of the IVR domain were the most frequently identified Cys residues as being highly reactive $(154,155)$. Furthermore, in vivo studies conducted with mutant Keap1 with substituted Cys revealed the functional importance of Cys273, Cys288 and Cys151 (156-159). These studies also allowed to establish that the Keap1-Nrf2 pathway can be up-regulated by various cellular stresses (oxidative stress, shear stress, ER stress) and structurally diverse small molecules (inducers) of endogenous (e.g., 15-deoxy- $\Delta^{12,14}$-prostaglandin $\mathrm{J}_{2}$, nitric oxide, and especially $\mathrm{H}_{2} \mathrm{O}_{2}$ ) as well as exogenous origin. Keap1-Nrf2 inducers were classified into 10 chemically distinct classes: oxidizable diphenols, phenylenediamines and quinones, Michael acceptors, isothiocyanates, thiocarbamates, trivalent arsenicals, dithiolethiones, hydroperoxides, vicinal dimercaptans, heavy metals, and polyenes (151).

It was early shown that $\mathrm{H}_{2} \mathrm{O}_{2}$ was able to activate the $\mathrm{Nrf2}$-dependent gene expression program, involved in detoxification pathways and in the oxidative stress response such as the ets-1 gene in a carcinoma cell model (160) or heme-oxygenase I in macrophages (161). The group of Toledano demonstrated that under basal or untreated conditions, Keap1 exists in two redox forms: a fully reduced form without apparent disulfide bonds among its various Cys residues, and a less abundant oxidized form with an intramolecular bond (162). 
Treatment with $200 \mu \mathrm{m} \mathrm{H}_{2} \mathrm{O}_{2}$, below toxicity levels, resulted in a transient increase in the levels of the oxidized form and in the appearance of two slow SDS-PAGE migrating forms corresponding one of them to a dimer between two Keap1 molecules. The Cys residues participating in the formation of the intramolecular disulfide bond were identified as Cys226 and Cys613, resulting in a long range intramolecular linking that spans the entire Kelch domain, and suggesting that in the fully folded state of Keap1, these two Cys are in close proximity. However, the intramolecular bond between Cys226 and Cys613 is not involved in Keap1 signaling function as a mutant with Cys226 substituted with serine still responded to tert-butylhydroquinone. The authors also identified Cys151 as the residue involved in the intermolecular bond between different Keap1 subunits. A Keap1 mutant carrying a Cys151to-serine substitution did not allow Nrf2 stabilization upon treatment with t-BHQ, indicating that Cys151-dependent Keap1 homodimer formation through a disulfide bond is important for Nrf2 activation in response to oxidants.

As expected for a signaling pathway, the oxidation of Keap1 by $\mathrm{H}_{2} \mathrm{O}_{2}$ is a reversible and very transient process that peaks at 5 min after treatment. This transient modification that reflects the short-lived nature of $\mathrm{H}_{2} \mathrm{O}_{2}$ parallels a slight but reproducible stabilization of Nrf2 (162). The reversibility of Keap1 oxidation is due to the recycling of the protein back to its reduced state by the Trx or the GSH/Grx systems. Interestingly, these two thiol redox pathways are not the only ones to reduce Keap1, as blocking simultaneously both of them delayed by $30 \mathrm{~min}$, but did not abolish, the reduction of Keap1.

As mentioned above (see section ' $\mathrm{H}_{2} \mathrm{O}_{2}$ reactivity with thiol groups'), protein Cys do not react easily with $\mathrm{H}_{2} \mathrm{O}_{2}$, and only Cys of specific sensor proteins such as Prxs or OxyR are directly oxidized by $\mathrm{H}_{2} \mathrm{O}_{2}$. This raises the question of whether oxidation of Keap1 involves direct modification by $\mathrm{H}_{2} \mathrm{O}_{2}$, in which case it would proceed through the oxidation of a Cys to a $\mathrm{SOH}$, condensation with a proximal Cys residue leading to a disulfide formation. At the 
present moment, this question is not solved. However, first attempts to identify modified Keap1 Cys by $\mathrm{H}_{2} \mathrm{O}_{2}$ using zebrafish larvae or embryos showed that, even though $\mathrm{H}_{2} \mathrm{O}_{2}$ could activate Nrf2 dependent genes in larvae, it failed to do so in embryos, suggesting that at least for the latter, an additional factor not present in the system was required to activate Nrf2 (163). It can be speculated that this factor could be a Prx or another protein directly modified by $\mathrm{H}_{2} \mathrm{O}_{2}$ that would then transduce the signal to Keap1.

To understand the mechanism of $\mathrm{Nrf} 2$ activation by oxidants such as $\mathrm{H}_{2} \mathrm{O}_{2}$ it is necessary to understand how modification of Cys 151 results in the accumulation of nuclear Nrf2 capable of binding to target genes (for a comprehensive review of the different proposed mechanisms please see (143). According to the predicted structure of the Keap1 BTB domain proposed by Fourquet and colleagues (162), Cys151 is not only remote from both the BTB dimerization interface and from the $\mathrm{E} 3$ ligase $\mathrm{Cul3}$, but it is also buried by four basic amino acids residues, which restrict its accessibility, but, at the same time, favor its reactivity towards electrophiles and oxidants. Under this perspective, Keap1 could be envisaged as a true sensor of $\mathrm{H}_{2} \mathrm{O}_{2}$. Oxidation of this residue to $\mathrm{SOH}$ in one monomer of Keap1 and subsequent disulfide formation with the thiol of Cys151 of another Keap1 monomer or, alternatively, between the two subunits of a non covalent Keap1 dimer (see below), would then affect the BTB canonical dimerization domain as well as the Cul3 interaction domain and, therefore, suppress Nrf2 ubiquitination and degradation. Based on this data we propose an Nrf2 activation model depicted in Figure 3D.

Using a newly developed quantitative Förster resonance energy transfer-based system using multiphoton fluorescence lifetime imaging, and choosing sulforaphane as an inducer, Baird and colleagues have proposed a mechanism for Nrf2 activation called "cyclic sequential attachment and regeneration model of Keap1-mediated degradation of Nrf2" (164). According to this model, in non-induced or basal conditions, newly 
translated Nrf2 would bind to a free Keap1 dimer through high-affinity Nrf2 ETGE motif giving rise to an open conformation of the Keap1-Nrf2 complex. In this conformation, Nrf2 is not ubiquitinated. After a certain period in the open conformation, Nrf2 would make contact with the other sububit of the Keap1 dimer through the low-affinity Nrf2 DLG motif. In this closed conformation, Nrf2 lysine residues are oriented in such a way that they are polyubiquitinated and, therefore, $\mathrm{Nrf} 2$ is released for degradation by the proteasome. Upon treatment with electrophils or oxidants, the modification or oxidation of reactive Cys residues of Keap1 would lead to conformational changes in Keap1, so that Nrf2 would still be bound to Keap1 in a closed conformation, but would no longer be aligned with the E2 ubiquitin-conjugating enzyme, so that ubiquitination would not occur, and bound Nrf2 would be sequestering Keap1. Then, newly translated Nrf2 would not be able to find free Keap1 molecules and would be targeted to the nucleus to activate genes. According to this model, any slight increase in Nrf2 levels would overload Keap1 and allow newly synthesized Nrf2 turning on the expression of target genes. The work of Toledano (162) suggested that the two Keap1 dimer species, one formed through non-redox BTB interactions and another one through a disulfide bond between Cys151 of two monomers, are mutually exclusive. Perhaps the closed uninduced conformation proposed by Baird and colleagues could correspond to a non covalent Keap1 dimer, not observed under Toledano's experimental denaturing conditions, and the closed induced conformation could correspond to a disulfide mediated/stabilized Keap1 dimer. However, as the nature of the inducing agents is different in both studies, different mechanisms may also exist to transduce the signal but using a common sensing Cys residue.

\section{GENETICALLY-ENCODED CYS-BASED $\mathrm{H}_{2} \mathrm{O}_{2}$ SENSORS}


Many small permeable fluorescent probes are used for monitoring $\mathrm{H}_{2} \mathrm{O}_{2}$ in living cells (for a review, see (165). Alternatively, the highly reactive character of some thiol groups from particular proteins has been recently used for the development of the third generation of redox-sensitive fluorescent proteins. These are genetically encoded redox-sensitive probes derived from green fluorescent protein (roGFPs), which are ratiometric tools that allow specific, quantitative, dynamic and compartment-specific observations of intracellular redox potential or $\mathrm{H}_{2} \mathrm{O}_{2}$. Wild-type GFP has a single emission peak ( $\max 509 \mathrm{~nm}$ ) and two excitation peaks, $395 \mathrm{~nm}$ (A-band) and $475 \mathrm{~nm}$ (B-band), reflecting a protonated neutral form or a deprotonated anionic form, respectively, of the phenol group at position 66 within the chromophore $(166,167)$. There is a variant favoring chromophore deprotonation, called enhanced GFP (EGFP), resulting from a S65T mutation, which shifts the major excitation peak to $488 \mathrm{~nm}(168)$. roGFPs are based on wild type GFP or EGFP, in which two Cys residues were placed into the positions S147 and Q204, resulting in roGFP1 and roGFP2, respectively (169). roGFPs equilibrate with the GSH/GSSG pool in a process apparently catalyzed by endogenous Grxs. Thus an increase of GSH oxidation leads to roGFP oxidation, resulting in an increase in the A-band and in a decrease in the B-band $(170,171)$. This behavior is reversible; consequently, reducing conditions provoke an opposite effect. While these probes were able to detect changes in the intracellular redox potential, their slow equilibration prevented their use to detect transient and rapid oxidative changes (172). With the purpose of improving equilibrating rates, a third generation of these probes was designed. These new roGFP derivatives are covalently fused to a redox catalyst, facilitating a fast and complete equilibration of the probe with a particular redox couple. Thus, Grx1-roGFP2 is a very specific probe for the $2 \mathrm{GSH} / \mathrm{GSSG}$ redox couple (Figure 4A) (173). To directly measure $\mathrm{H}_{2} \mathrm{O}_{2}$, the GPx-like Orp1 was fused to roGFP2 (roGFP2-Orp1) (Figure 4B) (174). 
As described above (see Section ' $\mathrm{H}_{2} \mathrm{O}_{2}$-activated transcription factors'), Orp1 is a GPx-like protein that upon $\mathrm{H}_{2} \mathrm{O}_{2}$-dependent Cys oxidation is able to transfer the redox signal to some Cys residues of the $S$. cerevisiae transcription factor, causing its nuclear accumulation and activation of an antioxidant response (75). Importantly, Orp1 is not only able to transfer the oxidation status to Yap1 but also to other proteins, such in this case to roGFP2. Thus, upon $\mathrm{H}_{2} \mathrm{O}_{2}$ fluctuations Orp1 Cys36 and 82 are oxidized to a disulfide bond. This disulfide is then transferred to roGFP2 through a thiol-disulfide exchange. It is worth pointing out that for this redox relay to occur, both Cys residues in Orp1 are required, which reinforces the idea that Ybp1 may be participating in promoting the direct Orp1-SOH-to-SH-Yap1 relay. Regarding the use of roGFP2-Orp1 as a peroxide sensor, it is also important to mention that every molecule of $\mathrm{H}_{2} \mathrm{O}_{2}$ is converted into a disulfide bridge in roGFP2 in a stoichiometric manner, transforming $\mathrm{H}_{2} \mathrm{O}_{2}$ concentrations in measurable fluorescent signals in living cells $(173)$.

Similarly, the HyPer probe was also engineered to specifically report intracellular $\mathrm{H}_{2} \mathrm{O}_{2}$ concentrations (Figure 4C) (175). In this case, the sensitive element of the probe is the regulatory domain of the transcription factor OxyR (OxyR-RD). Cys199 within OxyR-RD reacts with $\mathrm{H}_{2} \mathrm{O}_{2}$ to initially form a SOH derivative. This is highly unstable and rapidly condenses with Cys208 located in the same domain. Disulfide bond oxidation leads to an important conformational change involving the 205 to 222 peptidic residues. To construct HyPer, the circularly permuted yellow fluorescent protein (cpYFP) was inserted between the residues 205 and 206 of OxyR-RD, resulting in cpYFP-OxyR-RD (175). Hyper has two excitation peaks, with maximum values at $420 \mathrm{~nm}$ and $500 \mathrm{~nm}$, and one emission peak at 516 nm. $\mathrm{H}_{2} \mathrm{O}_{2}$-driven HyPer oxidation results in a decrease in the $420 \mathrm{~nm}$ peak concomitantly with a proportional increase in the $500 \mathrm{~nm}$ emission peak. So, as in the case of roGFP2Orp1, disulfide formation in the HyPer probe transduces $\mathrm{H}_{2} \mathrm{O}_{2}$ concentrations into 
measurable fluorescent signals in living cells. It is important however, to keep in mind that both Orp1 and OxyR are reduced by the Trx and/or GSH/Grx systems, respectively; consequently, these probes are not only reflecting a balance between $\mathrm{H}_{2} \mathrm{O}_{2}$-driven thiol oxidation but also of thiol reduction. Excellent Reviews on redox probes based on fluorescent proteins have been recently reported by Meyer and Dick (170) and by Lukyanov and Belousov (177).

\section{METHODOLOGIES TO STUDY REVERSIBLE CYS MODIFICATIONS}

The study of proteins with Cys residues undergoing redox modifications has been always a challenging task. Some time ago, this type of research was based on single protein analysis, which was often supported with the help of genetics (by gene deletion and/or site-directed mutagenesis). In the last few years, with the development of the proteomic field, it is becoming more and more common to find detailed analysis of reversible thiol oxidations in diverse environmental and genetic conditions in different organisms and cell types.

One of the main difficulties at the time of studying reversible Cys oxidations is to obtain a snapshot of the in vivo Cys redox status at a desired particular time. This is due to the highly reactive nature of the thiolate anion and to the dynamism of intracellular redox events. Therefore, before starting any proteomic procedure, it is necessary to block thiolate reactivity. Probably the best option is to perform cell lysis in the presence of trichloroacetic acid (TCA) (178), which not only rapidly protonates all redox-active thiolate anions by

shifting the $\mathrm{pH}$ below their $p K_{a}$, but also stops thiol-disulfide exchanges by precipitating and denaturing proteins $(179,180)$. Alternatively, although less efficiently, since thiolates are good nucleotides, membrane-permeable alkylating agents, such as iodoacetamide (IAM) or 
maleimide derivatives, are also used for freezing the thiol-redox status (a good review on this topic can be found in (178).

Once the thiolate reactivity is minimized by acidification and alkylation, several proteomic approaches have been undertaken to assess in vivo global redox changes of thiol proteomes, using different cellular backgrounds and/or environmental interventions.

Study of SOH modifications. SOH modifications can be directly detected taking advantage of the electrofilic character of the oxidized sulfur atom. Thus, sulfenic acids react with 5,5dimethyl-1,3-cyclohexanedione (dimedone) and other nucleophiles yielding thioethers. Dimedone and 1,3-cyclohexanediones in general provided the basis for the development of novel derivatized compounds incorporating biotin or fluorescent groups to allow direct trapping, tagging and visualization of proteins containing sulfenic acid modifications (181187). More recently, the non-dimedone related linear $\beta$-ketoesters were reported to have improved kinetics when compared to dimedone at physiological $\mathrm{pH}$, easy derivatization by click chemistry, and improved compatibility for downstream MS analysis, as tags can be removed by hydroxylamine (188). Other methodologies to study protein sulfenation include immunochemical detection $(189,190)$. Thus, sulfenic acids in proteins are first derivatized with dimedone, and then recognized by highly specific antibodies allowing direct visualization of sulfenic acid formation in cells.

Study of disulfide bond modifications. Diagonal SDS-PAGE, was adapted to identify cytoplasmic proteins which suffer disulfide bond formation upon oxidative stress treatment (191). This methodology consists on separating oxidized proteins in a first dimension by non-reducing electrophoresis. Then, a lane containing the separated proteins is excised from the gel and placed horizontally in a second gel to perform a second electrophoretic dimension 
under reducing conditions. This results in an atypical 2D gel containing a diagonal line of proteins representing the majority of proteins which do not form disulfide bonds. However, some proteins appear as spots in the right side of the diagonal, these are proteins forming inter-molecular disulfide bonds, (proteins migrating slower in the first dimension). In contrast, proteins forming intra-molecular disulfide bonds may migrate faster in the first dimension, appearing in the left side of the diagonal upon the second electrophoretic dimension. This approach was used to detect disulfide bond formation in a mammalian neuronal cell line exposed to different oxidative insults (191). However, a major intrinsic limitation to this technique is the use of $2 \mathrm{D}$ electrophoresis (see the following paragraph).

Study of general reversibly thiol oxidation: the biotin switch assay. To study thiol oxidations not only to $\mathrm{SOH}$ or disulfide bonds but also to other types of reversible oxidations, a different approach was designed, initially developed to detect Cys Snitrosylation (192), which was called the biotin switch assay. In this strategy, Cys oxidation is detected as an increase of probe incorporation in reducible thiols. Independently or having used TCA or not to block thiolate reactivity, all reduced Cys residues in the proteome are first blocked with an alkylating agent (IAM or maleimide). Then, reversibly oxidized thiols are reduced with a reducing agent and the newly appearing reduced Cys residues are alkylated with IAM- or maleimide-biotin derivatives. The use of biotin derivatives allows sample enrichment by affinity purification and therefore notable improvements in the sensitivity and the specificity of the technique. In spite of controversy due to lack of specificity, different types of reducing agents have been used to report different types of Cys modifications. Thus, SNOs can be detected upon incubation with ascorbate $/ \mathrm{CuCl}_{2}$ (193), improving selectivity when compared to ascorbate alone (194); sulfenated Cys can be specifically detected upon reduction with arsenite $(193,195)$, the C14S,C65Y doble mutant 
of E. coli Grx3 specifically reduces S-glutathionylated Cys (196); and dithiothreitol (DTT) or tris (2- carboxyethyl) phosphine hydrochloride (TCEP) non-specifically reduce all types of reversible thiol oxidations (197-199). This type of strategy, in combination with 2D electrophoresis, allowed the successful identification of many redox-sensitive proteins in different organisms, including bacteria (179), yeast (200) and cells from higher eukaryotes (201). Still, 2D electrophoresis is a major limitation of these techniques, since it lacks sensitivity, which results in the identification of only those proteins highly expressed in cells. Specificity is also a major issue, as determined using the new generation mass spectrometers: they are able to report the presence of several proteins in a single $2 \mathrm{D}$ gel spot, and it is impossible to discern which is the protein suffering thiol oxidation. Moreover, these methodologies are at best semi-quantitative, and they do not allow the identification of the Cys residues oxidized within the polypeptide.

\section{Gel free approaches, a step forward in the characterization of reversibly oxidized thiol}

proteomes. The incredible development of the proteomics field in the last few years, including quantitative proteomics, has paralleled the development of new methodologies for the detection and quantification of reversible thiol modifications. Thus, SNO Site Identification (SNOSID) was proposed as a gel-free extension of the biotin switch methodology (202). Peptides rather than proteins are enriched by avidin resin prior to mass spectrometry-based identification of only those peptides previously containing a SNO modification. A similar strategy, named SNO Resin Assisted Capture (SNO-RAC), proposed the capture of originally SNO-modified proteins with thiol-reactive beads, with an 'on-resin' trypsinization step prior to LC-MS/MS analysis (203). Still, due to the labile nature of the SNO modification, these indirect methodologies are nowadays being challenged by new experimental approaches involving the direct reaction of SNOs with phosphine 
derivatives (reviewed in $(204,205)$. Another sophisticated methodology recently developed which uses mass spectrometry for the identification of reversible Cys oxidations is GELSILOX (GEL-based Stable Isotope Labeling of Oxidized Cys) (206). After alkylation of reduced thiols in extracts, this method only uses SDS-PAGE to comprise a whole proteome in a single band; gel slices are then used as reaction chambers for all subsequent reactions (reduction, alkylation of oxidized thiols, protein digestion), and will avoid protein precipitations between the different steps. After trypsinization, peptides from two different biological samples are eluted from the gel and subjected to differential ${ }^{16} \mathrm{O} /{ }^{18} \mathrm{O}$-labeling prior to mass spectrometry. This method allows the quantification of reduced and oxidized Cys as well as protein abundance simultaneously in the same experiment.

The adaptation of the quantitative isotope coded affinity tag (ICAT) technology (207) to redox proteomics $(208,209)$ constitutes an important step in the characterization of reversibly oxidized thiol proteomes. ICAT moieties are alkylating agents consisting of an IAM linked to a biotin tag through a 9-carbon linker, which exists in an isotopically light $\left({ }^{12} \mathrm{C}\right.$-ICAT $)$ and a 9-Da-heavier isotopic form $\left({ }^{13} \mathrm{C}\right.$-ICAT $)$. Thus, by differential alkylation of samples, this technique was used either for the quantification of the absolute oxidation status of proteins in a single sample, which was called OxICAT (210), or for the comparison of two samples at once $(86,211)$.

In the OxICAT methodology, initially reduced Cys residues are labeled with light ICAT, whereas upon reduction, newly appearing reduced Cys are labeled with heavy ICAT. After trypsinization, the biotin side of the ICAT moiety allows affinity purification and enrichment of Cys-containing peptides, which are then processed by HPLC and quantified and identified by LC and tandem MS/MS analysis, respectively. Importantly, the fact that the light and heavy ICAT reagents are chemically identical allows them to co-elute from the HPLC system and to behave equally in the mass spectrometer. Thus, differences of 9-Da, or 
multiples of 9-Da, reflect the number of oxidized Cys in a peptide. Moreover, relative peak areas of a peptide containing a Cys labeled with both heavy and light ICAT reagents reflects its absolute oxidation status. Several are the strengths of this technique: it is quantitative, it allows the identification of thousands of peptides at the same time and the identification of the involved redox-sensitive Cys residues, as well as their in vivo oxidation status, and it is immune to changes in protein expression or protein turnover. In fact, it was successfully applied to detect reversible Cys oxidations in E. coli (210), in S. cerevisiae (212) or in Caenorhabditis elegans $(213,214)$. However, there are still some constraints, the main one being the high level of sample complexity reached with this type of approach. Thus, as more than $90 \%$ of intracellular Cys residues are in their reduced state (215), there is a big disproportion among Cys-containing peptides labeled with one of the ICAT reagents in comparison with the other one. To perform analysis, extensive sample fractionation is required, making data analysis difficult and time consuming, even requiring specific software development and qualified proteomic and bioinformatis personnel (210).

Sample complexity can be diminished if ICAT reagents are used for comparison of two samples at once. Thus, for the two samples to be compared, reduced thiols are blocked with an alkylating agent, and upon reduction of reversibly oxidized thiols, newly appearing thiols are labeled in one of the samples with the light ICAT reagent and in the other one with the heavy ICAT reagent. Then, the two samples are mixed in equal ratios, trypsinized, affinity purified and analyzed by LC-MS/MS. For each peptide, a ratio of Cys oxidation (ICAT ratio) is obtained by comparing the abundance of a particular peptide in one sample with the levels of the same peptide in the other sample. In this case, since only those peptides containing reversible oxidized thiols in both samples are labeled with ICAT reagents, the amount of Cys residues labeled with either ICAT reagent is approximately of the same order of magnitude, providing a sample with lower level of complexity, which 
considerably simplifies data analysis. A minor limitation of this approach, however, is that it is not as quantitative as the former. Still, this disadvantage can be overcome by adding a step of protein quantification. Thus, by combining ICAT labeling with N-terminal dimethyl labeling (216) (to determine the steady-state concentrations of individual proteins) we were able to quantify reversibly oxidized thiols in $S$. pombe upon oxidative stress and in different strain backgrounds (Figure 5) $(86,211)$.

What to expect from the analysis of reversibly oxidized thiol proteomes? The proteomic characterization of reversible thiol oxidations upon $\mathrm{H}_{2} \mathrm{O}_{2}$ treatment consistently showed oxidations of specific Cys residues of proteins, belonging to all subcellular compartments and to several functional categories (including antioxidant enzymes, cytoskeletal proteins, chaperones, ribosomal proteins, proteolytic proteins, and metabolic enzymes). The real meaning of Cys oxidation in many of these proteins remains to be proved, however speculations and the study of particular cases, such as GAPDH oxidation (for a review, see (26), probably indicates a metabolic adjustment to counteract the oxidative stress exerted. As an example, oxidation of enzymes of the glycolytic pathway, such as GAPDH, may promote a metabolic switch from glycolysis to the pentose phosphate pathway (a specialized route for the generation of NADPH, the major intracellular electron donor). Another important outcome from these experiments is the confirmation that thiol oxidation by $\mathrm{H}_{2} \mathrm{O}_{2}$ does not occur randomly in proteins. First, under physiological conditions, there is a certain percentage of proteins with Cys residues oxidized to reversible forms (5 to $10 \%$ of total thiols) (215); and second, upon oxidative treatment, only specific proteins, probably those with solvent exposed and low $p K_{a}$ Cys, are prone to increase their oxidized fraction. 


\section{CONCLUSIONS}

In recent years, there has been an increasing amount of literature regarding $\mathrm{H}_{2} \mathrm{O}_{2}$-dependent Cys oxidation linked to signaling. Several are the intracellular pathways that are triggered through changes in the redox status of particular Cys residues in proteins upon $\mathrm{H}_{2} \mathrm{O}_{2}$ stress. In prokaryotes and unicellular eukaryotes, these cascades are mainly devoted to trigger antioxidant responses that allow adaptation and/or survival to the encountered stress. In higher eukaryotes, the Keap1/Nrf2 complex regulates environmental stress-protective response, although $\mathrm{H}_{2} \mathrm{O}_{2}$ signaling mainly comes from endogenous sources, such as NADPH oxidases or mitochondria. However, there are still important gaps to be filled to fully understand the essence and the extent of reversible Cys oxidation linked to signaling events. With the development of new proteomic approaches for the characterization of posttranslational amino acid modifications, new clues are emerging regarding the nature of the modified proteins. However, it is still necessary to reach higher detection limits to encounter less abundant proteins which may be importantly regulated, especially under the low physiological concentrations of the oxidant. Moreover, major efforts have to be done to establish functional and phenotypical relationships among those proteins mapped on proteomic studies. 


\section{REFERENCES}

1. Imlay, J. A. (2003) Pathways of oxidative damage, Annu Rev Microbiol 57, 395418.

2. Stadtman, E. R., and Levine, R. L. (2000) Protein oxidation, Ann N Y Acad Sci 899, 191-208.

3. Fam, S. S., and Morrow, J. D. (2003) The isoprostanes: unique products of arachidonic acid oxidation-a review, Curr Med Chem 10, 1723-1740.

4. Evans, M. D., Dizdaroglu, M., and Cooke, M. S. (2004) Oxidative DNA damage and disease: induction, repair and significance, Mutat Res 567, 1-61.

5. D'Autreaux, B., and Toledano, M. B. (2007) ROS as signalling molecules: mechanisms that generate specificity in ROS homeostasis, Nat Rev Mol Cell Biol 8, 813-824.

6. Wood, P. M. (1988) The potential diagram for oxygen at $\mathrm{pH} 7$, Biochem J 253, 287-289.

7. Winterbourn, C. C., and Metodiewa, D. (1999) Reactivity of biologically important thiol compounds with superoxide and hydrogen peroxide, Free Radic Biol Med 27, 322-328.

8. Bigelow, D. J., and Squier, T. C. (2005) Redox modulation of cellular signaling and metabolism through reversible oxidation of methionine sensors in calcium regulatory proteins, Biochim Biophys Acta 1703, 121-134. 
9. Manta, B., Hugo, M., Ortiz, C., Ferrer-Sueta, G., Trujillo, M., and Denicola, A. (2009) The peroxidase and peroxynitrite reductase activity of human erythrocyte peroxiredoxin 2, Arch Biochem Biophys 484, 146-154.

10. Vivancos, A. P., Jara, M., Zuin, A., Sanso, M., and Hidalgo, E. (2006) Oxidative stress in Schizosaccharomyces pombe: different $\mathrm{H}_{2} \mathrm{O}_{2}$ levels, different response pathways, Mol Genet Genomics 276, 495-502.

11. Hall, A., Karplus, P. A., and Poole, L. B. (2009) Typical 2-Cys peroxiredoxins-structures, mechanisms and functions, Febs $J$ 276, 2469-2477.

12. Rhee, S. G., Chae, H. Z., and Kim, K. (2005) Peroxiredoxins: a historical overview and speculative preview of novel mechanisms and emerging concepts in cell signaling, Free Radic Biol Med 38, 1543-1552.

13. Marino, S. M., and Gladyshev, V. N. (2010) Cysteine function governs its conservation and degeneration and restricts its utilization on protein surfaces, $J$ Mol Biol 404, 902-916.

14. Jacob, C., Giles, G. I., Giles, N. M., and Sies, H. (2003) Sulfur and selenium: the role of oxidation state in protein structure and function, Angew Chem Int Ed Engl 42, 4742-4758.

15. Yang, K. S., Kang, S. W., Woo, H. A., Hwang, S. C., Chae, H. Z., Kim, K., and Rhee, S. G. (2002) Inactivation of human peroxiredoxin I during catalysis as the result of the oxidation of the catalytic site cysteine to cysteine-sulfinic acid, $J$ Biol Chem 277, 38029-38036. 
16. Woo, H. A., Jeong, W., Chang, T. S., Park, K. J., Park, S. J., Yang, J. S., and Rhee, S. G. (2005) Reduction of cysteine sulfinic acid by sulfiredoxin is specific to 2-cys peroxiredoxins, $J$ Biol Chem 280, 3125-3128.

17. Biteau, B., Labarre, J., and Toledano, M. B. (2003) ATP-dependent reduction of cysteine-sulphinic acid by S. cerevisiae sulphiredoxin, Nature 425, 980-984.

18. Stone, J. R., and Yang, S. (2006) Hydrogen peroxide: a signaling messenger, Antioxid Redox Signal 8, 243-270.

19. Forman, H. J., Maiorino, M., and Ursini, F. (2010) Signaling functions of reactive oxygen species, Biochemistry 49, 835-842.

20. Roos, G., Foloppe, N., and Messens, J. (2013) Understanding the pK(a) of redox cysteines: the key role of hydrogen bonding, Antioxid Redox Signal 18, 94-127.

21. Ferrer-Sueta, G., Manta, B., Botti, H., Radi, R., Trujillo, M., and Denicola, A. (2011) Factors affecting protein thiol reactivity and specificity in peroxide reduction, Chem Res Toxicol 24, 434-450.

22. Gilbert, H. F. (1990) Molecular and cellular aspects of thiol-disulfide exchange, Adv Enzymol Relat Areas Mol Biol 63, 69-172.

23. Marino, S. M., and Gladyshev, V. N. (2012) Analysis and functional prediction of reactive cysteine residues, $J$ Biol Chem 287, 4419-4425.

24. Netto, L. E., de Oliveira, M. A., Monteiro, G., Demasi, A. P., Cussiol, J. R., Discola, K. F., Demasi, M., Silva, G. M., Alves, S. V., Faria, V. G., and Horta, B. B. (2007) Reactive cysteine in proteins: protein folding, antioxidant defense, 
redox signaling and more, Comp Biochem Physiol C Toxicol Pharmacol 146, 180-193.

25. Benesch, R. E., and Benesch, R. (1955) The Acid Strength of the -SH Group in Cysteine and Related Compounds, J. Am. Chem. Soc. 77, 5877-5881.

26. Tristan, C., Shahani, N., Sedlak, T. W., and Sawa, A. (2011) The diverse functions of GAPDH: views from different subcellular compartments, Cell Signal 23, 317-323.

27. Ostman, A., Frijhoff, J., Sandin, A., and Bohmer, F. D. (2011) Regulation of protein tyrosine phosphatases by reversible oxidation, $J$ Biochem 150, 345-356.

28. Seaver, L. C., and Imlay, J. A. (2001) Alkyl hydroperoxide reductase is the primary scavenger of endogenous hydrogen peroxide in Escherichia coli, $J$ Bacteriol 183, 7173-7181.

29. Low, F. M., Hampton, M. B., Peskin, A. V., and Winterbourn, C. C. (2007) Peroxiredoxin 2 functions as a noncatalytic scavenger of low-level hydrogen peroxide in the erythrocyte, Blood 109, 2611-2617.

30. Mishra, S., and Imlay, J. (2012) Why do bacteria use so many enzymes to scavenge hydrogen peroxide?, Arch Biochem Biophys 525, 145-160.

31. Karplus, P. A., and Hall, A. (2007) Structural survey of the peroxiredoxins, Subcell Biochem 44, 41-60.

32. Hall, A., Nelson, K., Poole, L. B., and Karplus, P. A. (2011) Structure-based insights into the catalytic power and conformational dexterity of peroxiredoxins, Antioxid Redox Signal 15, 795-815. 
33. Winterbourn, C. C., and Hampton, M. B. (2008) Thiol chemistry and specificity in redox signaling, Free Radic Biol Med 45, 549-561.

34. Winterbourn, C. C. (2008) Reconciling the chemistry and biology of reactive oxygen species, Nat Chem Biol 4, 278-286.

35. Adimora, N. J., Jones, D. P., and Kemp, M. L. (2010) A model of redox kinetics implicates the thiol proteome in cellular hydrogen peroxide responses, Antioxid Redox Signal 13, 731-743.

36. Jara, M., Vivancos, A. P., Calvo, I. A., Moldon, A., Sanso, M., and Hidalgo, E. (2007) The peroxiredoxin Tpx1 is essential as a $\mathrm{H} 2 \mathrm{O} 2$ scavenger during aerobic growth in fission yeast, Mol Biol Cell 18, 2288-2295.

37. Calvo, I. A., Boronat, S., Domenech, A., Garcia-Santamarina, S., Ayte, J., and Hidalgo, E. (2013) Dissection of a redox relay: $\mathrm{H}_{2} \mathrm{O}_{2}$-dependent activation of the transcription factor Pap1 through the peroxidatic Tpx1-thioredoxin cycle, Cell Rep 5, 1413-1424.

38. Vivancos, A. P., Castillo, E. A., Biteau, B., Nicot, C., Ayte, J., Toledano, M. B., and Hidalgo, E. (2005) A cysteine-sulfinic acid in peroxiredoxin regulates $\mathrm{H}_{2} \mathrm{O}_{2}$ sensing by the antioxidant Pap1 pathway, Proc Natl Acad Sci U S A 102, 88758880.

39. Calvo, I. A., Ayte, J., and Hidalgo, E. (2013) Reversible thiol oxidation in the $\mathrm{H}_{2} \mathrm{O}_{2}$-dependent activation of the transcription factor Pap1, J Cell Sci 126, 22792284. 
40. Meyer, Y., Buchanan, B. B., Vignols, F., and Reichheld, J. P. (2009)

Thioredoxins and glutaredoxins: unifying elements in redox biology, Annu Rev Genet 43, 335-367.

41. Holmgren, A. (1985) Thioredoxin, Annu Rev Biochem 54, 237-271.

42. Pan, J. L., and Bardwell, J. C. (2006) The origami of thioredoxin-like folds, Protein Sci 15, 2217-2227.

43. Holmgren, A., Soderberg, B. O., Eklund, H., and Branden, C. I. (1975) Threedimensional structure of Escherichia coli thioredoxin-S2 to 2.8 A resolution, Proc Natl Acad Sci U S A 72, 2305-2309.

44. Holmgren, A. (1995) Thioredoxin structure and mechanism: conformational changes on oxidation of the active-site sulfhydryls to a disulfide, Structure 3, 239-243.

45. Eklund, H., Cambillau, C., Sjoberg, B. M., Holmgren, A., Jornvall, H., Hoog, J. O., and Branden, C. I. (1984) Conformational and functional similarities between glutaredoxin and thioredoxins, Embo J 3, 1443-1449.

46. Berndt, C., Lillig, C. H., and Holmgren, A. (2008) Thioredoxins and glutaredoxins as facilitators of protein folding, Biochim Biophys Acta 1783, 641650.

47. Krause, G., Lundstrom, J., Barea, J. L., Pueyo de la Cuesta, C., and Holmgren, A. (1991) Mimicking the active site of protein disulfide-isomerase by substitution of proline 34 in Escherichia coli thioredoxin, J Biol Chem 266, 9494-9500. 
48. Aslund, F., Berndt, K. D., and Holmgren, A. (1997) Redox potentials of glutaredoxins and other thiol-disulfide oxidoreductases of the thioredoxin superfamily determined by direct protein-protein redox equilibria, $\mathrm{J}$ Biol Chem 272, 30780-30786.

49. Wunderlich, M., Jaenicke, R., and Glockshuber, R. (1993) The redox properties of protein disulfide isomerase (DsbA) of Escherichia coli result from a tense conformation of its oxidized form, J Mol Biol 233, 559-566.

50. Cheng, Z., Zhang, J., Ballou, D. P., and Williams, C. H., Jr. (2011) Reactivity of thioredoxin as a protein thiol-disulfide oxidoreductase, Chem Rev 111, 57685783.

51. Moore, E. C., Reichard, P., and Thelander, L. (1964) Enzymatic Synthesis of Deoxyribonucleotides.V. Purification and Properties of Thioredoxin Reductase from Escherichia Coli B, J Biol Chem 239, 3445-3452.

52. Holmgren, A. (1976) Hydrogen donor system for Escherichia coli ribonucleoside-diphosphate reductase dependent upon glutathione, Proc Natl Acad Sci U S A 73, 2275-2279.

53. Collet, J. F., and Messens, J. (2010) Structure, function, and mechanism of thioredoxin proteins, Antioxid Redox Signal 13, 1205-1216.

54. Kallis, G. B., and Holmgren, A. (1980) Differential reactivity of the functional sulfhydryl groups of cysteine-32 and cysteine-35 present in the reduced form of thioredoxin from Escherichia coli, J Biol Chem 255, 10261-10265. 
55. Holmgren, A., and Aslund, F. (1995) Glutaredoxin, Methods Enzymol 252, 283292.

56. Holmgren, A., and Bjornstedt, M. (1995) Thioredoxin and thioredoxin reductase, Methods Enzymol 252, 199-208.

57. Lillig, C. H., Berndt, C., and Holmgren, A. (2008) Glutaredoxin systems, Biochim Biophys Acta 1780, 1304-1317.

58. Toledano, M. B., Kumar, C., Le Moan, N., Spector, D., and Tacnet, F. (2007) The system biology of thiol redox system in Escherichia coli and yeast: differential functions in oxidative stress, iron metabolism and DNA synthesis, FEBS Lett 581, 3598-3607.

59. Russel, M., Model, P., and Holmgren, A. (1990) Thioredoxin or glutaredoxin in Escherichia coli is essential for sulfate reduction but not for deoxyribonucleotide synthesis, J Bacteriol 172, 1923-1929.

60. Ortenberg, R., Gon, S., Porat, A., and Beckwith, J. (2004) Interactions of glutaredoxins, ribonucleotide reductase, and components of the DNA replication system of Escherichia coli, Proc Natl Acad Sci US A 101, 7439-7444.

61. Aslund, F., Ehn, B., Miranda-Vizuete, A., Pueyo, C., and Holmgren, A. (1994) Two additional glutaredoxins exist in Escherichia coli: glutaredoxin 3 is a hydrogen donor for ribonucleotide reductase in a thioredoxin/glutaredoxin 1 double mutant, Proc Natl Acad Sci U S A 91, 9813-9817. 
62. Prinz, W. A., Aslund, F., Holmgren, A., and Beckwith, J. (1997) The role of the thioredoxin and glutaredoxin pathways in reducing protein disulfide bonds in the Escherichia coli cytoplasm, J Biol Chem 272, 15661-15667.

63. Kolberg, M., Strand, K. R., Graff, P., and Andersson, K. K. (2004) Structure, function, and mechanism of ribonucleotide reductases, Biochim Biophys Acta 1699, 1-34.

64. Arenas, F. A., Diaz, W. A., Leal, C. A., Perez-Donoso, J. M., Imlay, J. A., and Vasquez, C. C. (2010) The Escherichia coli btuE gene, encodes a glutathione peroxidase that is induced under oxidative stress conditions, Biochem Biophys Res Commun 398, 690-694.

65. Aslund, F., Zheng, M., Beckwith, J., and Storz, G. (1999) Regulation of the OxyR transcription factor by hydrogen peroxide and the cellular thiol-disulfide status, Proc Natl Acad Sci U S A 96, 6161-6165.

66. Tao, K. (1999) In vivo oxidation-reduction kinetics of OxyR, the transcriptional activator for an oxidative stress-inducible regulon in Escherichia coli, FEBS Lett. 457, 90-92.

67. Zheng, M., Aslund, F., and Storz, G. (1998) Activation of the OxyR transcription factor by reversible disulfide bond formation, Science 279, 17181721.

68. Draculic, T., Dawes, I. W., and Grant, C. M. (2000) A single glutaredoxin or thioredoxin gene is essential for viability in the yeast Saccharomyces cerevisiae, Mol Microbiol 36, 1167-1174. 
69. Muller, E. G. (1991) Thioredoxin deficiency in yeast prolongs S phase and shortens the G1 interval of the cell cycle, J Biol Chem 266, 9194-9202.

70. Camier, S., Ma, E., Leroy, C., Pruvost, A., Toledano, M., and MarsolierKergoat, M. C. (2007) Visualization of ribonucleotide reductase catalytic oxidation establishes thioredoxins as its major reductants in yeast, Free Radic Biol Med 42, 1008-1016.

71. Chae, H. Z., Chung, S. J., and Rhee, S. G. (1994) Thioredoxin-dependent peroxide reductase from yeast, $J$ Biol Chem 269, 27670-27678.

72. Lee, J., Spector, D., Godon, C., Labarre, J., and Toledano, M. B. (1999) A new antioxidant with alkyl hydroperoxide defense properties in yeast, $J$ Biol Chem $274,4537-4544$.

73. Verdoucq, L., Vignols, F., Jacquot, J. P., Chartier, Y., and Meyer, Y. (1999) In vivo characterization of a thioredoxin $\mathrm{h}$ target protein defines a new peroxiredoxin family, J Biol Chem 274, 19714-19722.

74. Tanaka, T., Izawa, S., and Inoue, Y. (2005) GPX2, encoding a phospholipid hydroperoxide glutathione peroxidase homologue, codes for an atypical 2-Cys peroxiredoxin in Saccharomyces cerevisiae, J Biol Chem 280, 42078-42087.

75. Delaunay, A., Pflieger, D., Barrault, M. B., Vinh, J., and Toledano, M. B. (2002) A thiol peroxidase is an $\mathrm{h}(2) \mathrm{o}(2)$ receptor and redox-transducer in gene activation, Cell 111, 471-481. 
76. Kim, J. S., Bang, M. A., Lee, S., Chae, H. Z., and Kim, K. (2010) Distinct functional roles of peroxiredoxin isozymes and glutathione peroxidase from fission yeast, Schizosaccharomyces pombe, BMB Rep 43, 170-175.

77. Lee, S. Y., Song, J. Y., Kwon, E. S., and Roe, J. H. (2008) Gpx1 is a stationary phase-specific thioredoxin peroxidase in fission yeast, Biochem Biophys Res Commun 367, 67-71.

78. Day, A. M., Brown, J. D., Taylor, S. R., Rand, J. D., Morgan, B. A., and Veal, E. A. (2012) Inactivation of a peroxiredoxin by hydrogen peroxide is critical for thioredoxin-mediated repair of oxidized proteins and cell survival, Mol Cell 45, 398-408.

79. Izawa, S., Maeda, K., Sugiyama, K., Mano, J., Inoue, Y., and Kimura, A. (1999) Thioredoxin deficiency causes the constitutive activation of Yap1, an AP-1-like transcription factor in Saccharomyces cerevisiae, J Biol Chem 274, 2845928465.

80. Vivancos, A. P., Castillo, E. A., Jones, N., Ayte, J., and Hidalgo, E. (2004) Activation of the redox sensor Pap1 by hydrogen peroxide requires modulation of the intracellular oxidant concentration, Mol Microbiol 52, 1427-1435.

81. Grant, C. M., MacIver, F. H., and Dawes, I. W. (1996) Glutathione is an essential metabolite required for resistance to oxidative stress in the yeast Saccharomyces cerevisiae, Curr Genet 29, 511-515.

82. Kumar, C., Igbaria, A., D'Autreaux, B., Planson, A. G., Junot, C., Godat, E., Bachhawat, A. K., Delaunay-Moisan, A., and Toledano, M. B. (2011) 
Glutathione revisited: a vital function in iron metabolism and ancillary role in thiol-redox control, Embo J 30, 2044-2056.

83. Sipos, K., Lange, H., Fekete, Z., Ullmann, P., Lill, R., and Kispal, G. (2002) Maturation of cytosolic iron-sulfur proteins requires glutathione, $J$ Biol Chem 277, 26944-26949.

84. Derman, A. I., Prinz, W. A., Belin, D., and Beckwith, J. (1993) Mutations that allow disulfide bond formation in the cytoplasm of Escherichia coli, Science $262,1744-1747$.

85. Stewart, E. J., Aslund, F., and Beckwith, J. (1998) Disulfide bond formation in the Escherichia coli cytoplasm: an in vivo role reversal for the thioredoxins, Embo J 17, 5543-5550.

86. Garcia-Santamarina, S., Boronat, S., Calvo, I. A., Rodriguez-Gabriel, M., Ayte, J., Molina, H., and Hidalgo, E. (2013) Is oxidized thioredoxin a major trigger for cysteine oxidation? Clues from a redox proteomics approach, Antioxid Redox Signal 18, 1549-1556.

87. Schell, M. A. (1993) Molecular biology of the LysR family of transcriptional regulators, Annu Rev Microbiol 47, 597-626.

88. Morikawa, K., Ohniwa, R. L., Kim, J., Maruyama, A., Ohta, T., and Takeyasu, K. (2006) Bacterial nucleoid dynamics: oxidative stress response in Staphylococcus aureus, Genes Cells 11, 409-423.

89. Hahn, J. S., Oh, S. Y., and Roe, J. H. (2002) Role of OxyR as a peroxide-sensing positive regulator in Streptomyces coelicolor A3(2), J Bacteriol 184, 5214-5222. 
90. Lee, C., Lee, S. M., Mukhopadhyay, P., Kim, S. J., Lee, S. C., Ahn, W. S., Yu, M. H., Storz, G., and Ryu, S. E. (2004) Redox regulation of OxyR requires specific disulfide bond formation involving a rapid kinetic reaction path, Nat Struct Mol Biol 11, 1179-1185.

91. Kona, J., and Brinck, T. (2006) A combined molecular dynamics simulation and quantum chemical study on the mechanism for activation of the OxyR transcription factor by hydrogen peroxide, Org Biomol Chem 4, 3468-3478.

92. Kullik, I., Toledano, M. B., Tartaglia, L. A., and Storz, G. (1995) Mutational analysis of the redox-sensitive transcriptional regulator OxyR: regions important for oxidation and transcriptional activation, J.Bacteriol. 177, 1275-1284.

93. Kullik, I., Stevens, J., Toledano, M. B., and Storz, G. (1995) Mutational analysis of the redox-sensitive transcriptional regulator OxyR: regions important for DNA binding and multimerization, J Bacteriol 177, 1285-1291.

94. Wang, X., Mukhopadhyay, P., Wood, M. J., Outten, F. W., Opdyke, J. A., and Storz, G. (2006) Mutational analysis to define an activating region on the redoxsensitive transcriptional regulator OxyR, J Bacteriol 188, 8335-8342.

95. Antelmann, H., and Helmann, J. D. (2011) Thiol-based redox switches and gene regulation, Antioxid Redox Signal 14, 1049-1063.

96. Seth, D., Hausladen, A., Wang, Y. J., and Stamler, J. S. (2012) Endogenous protein S-Nitrosylation in E. coli: regulation by OxyR, Science 336, 470-473. 
97. Chiang, S. M., and Schellhorn, H. E. (2012) Regulators of oxidative stress response genes in Escherichia coli and their functional conservation in bacteria, Arch Biochem Biophys 525, 161-169.

98. Liu, Y., Bauer, S. C., and Imlay, J. A. (2011) The YaaA protein of the Escherichia coli OxyR regulon lessens hydrogen peroxide toxicity by diminishing the amount of intracellular unincorporated iron, J Bacteriol 193, 2186-2196.

99. Zheng, M., Doan, B., Schneider, T. D., and Storz, G. (1999) OxyR and SoxRS regulation of fur, J.Bacteriol. 181, 4639-4643.

100. Zheng, M., Wang, X., Templeton, L. J., Smulski, D. R., LaRossa, R. A., and Storz, G. (2001) DNA microarray-mediated transcriptional profiling of the Escherichia coli response to hydrogen peroxide, J Bacteriol 183, 4562-4570.

101. Storz, G., Tartaglia, L. A., and Ames, B. N. (1990) Transcriptional regulator of oxidative stress-inducible genes: direct activation by oxidation, Science 248 , 189-194.

102. Tartaglia, L. A., Gimeno, C. J., Storz, G., and Ames, B. N. (1992) Multidegenerate DNA recognition by the OxyR transcriptional regulator, J.Biol.Chem. 267, 2038-2045.

103. Toledano, M. B., Kullik, I., Trinh, F., Baird, P. T., Schneider, T. D., and Storz, G. (1994) Redox-dependent shift of OxyR-DNA contacts along an extended DNA-binding site: a mechanism for differential promoter selection, Cell 78, 897-909. 
104. Choi, H., Kim, S., Mukhopadhyay, P., Cho, S., Woo, J., Storz, G., and Ryu, S. E. (2001) Structural basis of the redox switch in the OxyR transcription factor, Cell 105, 103-113.

105. Jang, H. H., Lee, K. O., Chi, Y. H., Jung, B. G., Park, S. K., Park, J. H., Lee, J. R., Lee, S. S., Moon, J. C., Yun, J. W., Choi, Y. O., Kim, W. Y., Kang, J. S., Cheong, G. W., Yun, D. J., Rhee, S. G., Cho, M. J., and Lee, S. Y. (2004) Two enzymes in one; two yeast peroxiredoxins display oxidative stress-dependent switching from a peroxidase to a molecular chaperone function, Cell 117, 625635.

106. Roy, A., Kucukural, A., and Zhang, Y. (2010) I-TASSER: a unified platform for automated protein structure and function prediction, Nat Protoc 5, 725-738.

107. Gusarov, I., and Nudler, E. (2012) S-nitrosylation signaling in Escherichia coli, Sci Signal 5, pe26.

108. Ryu, S. E. (2012) Structural mechanism of disulphide bond-mediated redox switches, J Biochem 151, 579-588.

109. Kim, S. O., Merchant, K., Nudelman, R., Beyer, W. F., Jr., Keng, T., DeAngelo, J., Hausladen, A., and Stamler, J. S. (2002) OxyR: a molecular code for redoxrelated signaling, Cell 109, 383-396.

110. Hausladen, A., Privalle, C. T., Keng, T., DeAngelo, J., and Stamler, J. S. (1996) Nitrosative stress: activation of the transcription factor OxyR, Cell 86, 719-729.

111. Haridas, V., Kim, S. O., Nishimura, G., Hausladen, A., Stamler, J. S., and Gutterman, J. U. (2005) Avicinylation (thioesterification): a protein modification 
that can regulate the response to oxidative and nitrosative stress, Proc Natl Acad Sci U S A 102, 10088-10093.

112. Chen, H., Xu, G., Zhao, Y., Tian, B., Lu, H., Yu, X., Xu, Z., Ying, N., Hu, S., and Hua, Y. (2008) A novel OxyR sensor and regulator of hydrogen peroxide stress with one cysteine residue in Deinococcus radiodurans, PLoS One 3, e1602.

113. Yin, L., Wang, L., Lu, H., Xu, G., Chen, H., Zhan, H., Tian, B., and Hua, Y. (2010) DRA0336, another OxyR homolog, involved in the antioxidation mechanisms in Deinococcus radiodurans, J Microbiol 48, 473-479.

114. Moye-Rowley, W. S., Harshman, K. D., and Parker, C. S. (1989) Yeast YAP1 encodes a novel form of the jun family of transcriptional activator proteins, Genes Dev. 3, 283-292.

115. Schnell, N., Krems, B., and Entian, K. D. (1992) The PAR1 (YAP1/SNQ3) gene of Saccharomyces cerevisiae, a c-jun homologue, is involved in oxygen metabolism, Curr.Genet. 21, 269-273.

116. Kuge, S., and Jones, N. (1994) YAP1 dependent activation of TRX2 is essential for the response of Saccharomyces cerevisiae to oxidative stress by hydroperoxides, EMBO J. 13, 655-664.

117. Gasch, A. P., Spellman, P. T., Kao, C. M., Carmel-Harel, O., Eisen, M. B., Storz, G., Botstein, D., and Brown, P. O. (2000) Genomic expression programs in the response of yeast cells to environmental changes, Mol.Biol.Cell 11, 42414257. 
118. Kuge, S., Jones, N., and Nomoto, A. (1997) Regulation of yAP-1 nuclear localization in response to oxidative stress, EMBO J. 16, 1710-1720.

119. Kuge, S., Toda, T., Iizuka, N., and Nomoto, A. (1998) Crm1 (XpoI) dependent nuclear export of the budding yeast transcription factor yAP-1 is sensitive to oxidative stress, Genes Cells 3, 521-532.

120. Yan, C., Lee, L. H., and Davis, L. I. (1998) Crm1p mediates regulated nuclear export of a yeast AP-1-like transcription factor, EMBO J. 17, 7416-7429.

121. Delaunay, A., Isnard, A. D., and Toledano, M. B. (2000) H(2)O(2) sensing through oxidation of the Yap1 transcription factor, EMBO J. 19, 5157-5166.

122. Ma, L. H., Takanishi, C. L., and Wood, M. J. (2007) Molecular mechanism of oxidative stress perception by the Orp1 protein, J Biol Chem 282, 31429-31436.

123. Veal, E. A., Ross, S. J., Malakasi, P., Peacock, E., and Morgan, B. A. (2003) Ybp1 is required for the hydrogen peroxide-induced oxidation of the Yap1 transcription factor, J Biol Chem 278, 30896-30904.

124. Gulshan, K., Rovinsky, S. A., Coleman, S. T., and Moye-Rowley, W. S. (2005) Oxidant-specific folding of Yap1p regulates both transcriptional activation and nuclear localization, J Biol Chem 280, 40524-40533.

125. Gulshan, K., Lee, S. S., and Moye-Rowley, W. S. (2011) Differential oxidant tolerance determined by the key transcription factor Yap1 is controlled by levels of the Yap1-binding protein, Ybp1, J Biol Chem 286, 34071-34081.

126. Wood, M. J., Storz, G., and Tjandra, N. (2004) Structural basis for redox regulation of Yap1 transcription factor localization, Nature 430, 917-921. 
127. Okazaki, S., Tachibana, T., Naganuma, A., Mano, N., and Kuge, S. (2007) Multistep disulfide bond formation in Yap1 is required for sensing and transduction of $\mathrm{H}_{2} \mathrm{O}_{2}$ stress signal, Mol Cell 27, 675-688.

128. Wood, M. J., Andrade, E. C., and Storz, G. (2003) The redox domain of the Yap1p transcription factor contains two disulfide bonds, Biochemistry 42, 11982-11991.

129. Mason, J. T., Kim, S. K., Knaff, D. B., and Wood, M. J. (2006) Thermodynamic basis for redox regulation of the Yap1 signal transduction pathway, Biochemistry 45, 13409-13417.

130. Ross, S. J., Findlay, V. J., Malakasi, P., and Morgan, B. A. (2000) Thioredoxin peroxidase is required for the transcriptional response to oxidative stress in budding yeast [In Process Citation], Mol.Biol.Cell 11, 2631-2642.

131. Tachibana, T., Okazaki, S., Murayama, A., Naganuma, A., Nomoto, A., and Kuge, S. (2009) A major peroxiredoxin-induced activation of Yap1 transcription factor is mediated by reduction-sensitive disulfide bonds and reveals a low level of transcriptional activation, J Biol Chem 284, 4464-4472.

132. Kudo, N., Taoka, H., Toda, T., Yoshida, M., and Horinouchi, S. (1999) A novel nuclear export signal sensitive to oxidative stress in the fission yeast transcription factor Pap1, J.Biol.Chem. 274, 15151-15158.

133. Toda, T., Shimanuki, M., and Yanagida, M. (1991) Fission yeast genes that confer resistance to staurosporine encode an AP-1-like transcription factor and a protein kinase related to the mammalian ERK1/MAP2 and budding yeast FUS3 and KSS1 kinases, Genes Dev. 5, 60-73. 
134. Toone, W. M., Kuge, S., Samuels, M., Morgan, B. A., Toda, T., and Jones, N. (1998) Regulation of the fission yeast transcription factor Pap1 by oxidative stress: requirement for the nuclear export factor Crm1 (Exportin) and the stressactivated MAP kinase Sty1/Spc1 [published erratum appears in Genes Dev 1998 Aug 15;12(16):2650] [see comments], Genes Dev. 12, 1453-1463.

135. Castillo, E. A., Ayte, J., Chiva, C., Moldon, A., Carrascal, M., Abian, J., Jones, N., and Hidalgo, E. (2002) Diethylmaleate activates the transcription factor Pap1 by covalent modification of critical cysteine residues, Mol Microbiol 45, 243254.

136. Bozonet, S. M., Findlay, V. J., Day, A. M., Cameron, J., Veal, E. A., and Morgan, B. A. (2005) Oxidation of a eukaryotic 2-Cys peroxiredoxin is a molecular switch controlling the transcriptional response to increasing levels of hydrogen peroxide, J Biol Chem 280, 23319-23327.

137. Chen, D., Wilkinson, C. R., Watt, S., Penkett, C. J., Toone, W. M., Jones, N., and Bahler, J. (2008) Multiple pathways differentially regulate global oxidative stress responses in fission yeast, Mol Biol Cell 19, 308-317.

138. Calvo, I. A., Garcia, P., Ayte, J., and Hidalgo, E. (2012) The transcription factors Pap1 and Prr1 collaborate to activate antioxidant, but not drug tolerance, genes in response to $\mathrm{H}_{2} \mathrm{O}_{2}$, Nucleic Acids Res 40, 4816-4824.

139. Castillo, E. A., Vivancos, A. P., Jones, N., Ayte, J., and Hidalgo, E. (2003) Schizosaccharomyces pombe cells lacking the Ran-binding protein Hbal show a multidrug resistance phenotype due to constitutive nuclear accumulation of Pap1, J Biol Chem 278, 40565-40572. 
140. Kwak, M. K., Cho, J. M., Huang, B., Shin, S., and Kensler, T. W. (2007) Role of increased expression of the proteasome in the protective effects of sulforaphane against hydrogen peroxide-mediated cytotoxicity in murine neuroblastoma cells, Free Radic Biol Med 43, 809-817.

141. Nguyen, T., Sherratt, P. J., and Pickett, C. B. (2003) Regulatory mechanisms controlling gene expression mediated by the antioxidant response element, Annu Rev Pharmacol Toxicol 43, 233-260.

142. Motohashi, H., O'Connor, T., Katsuoka, F., Engel, J. D., and Yamamoto, M. (2002) Integration and diversity of the regulatory network composed of Maf and CNC families of transcription factors, Gene 294, 1-12.

143. Baird, L., and Dinkova-Kostova, A. T. (2011) The cytoprotective role of the Keap1-Nrf2 pathway, Arch Toxicol 85, 241-272.

144. Kobayashi, M., and Yamamoto, M. (2005) Molecular mechanisms activating the Nrf2-Keap1 pathway of antioxidant gene regulation, Antioxid Redox Signal 7, $385-394$.

145. Taguchi, K., Motohashi, H., and Yamamoto, M. (2011) Molecular mechanisms of the Keap1-Nrf2 pathway in stress response and cancer evolution, Genes Cells $16,123-140$.

146. Kobayashi, A., Kang, M. I., Watai, Y., Tong, K. I., Shibata, T., Uchida, K., and Yamamoto, M. (2006) Oxidative and electrophilic stresses activate Nrf2 through inhibition of ubiquitination activity of Keap1, Mol Cell Biol 26, 221-229. 
147. Zipper, L. M., and Mulcahy, R. T. (2002) The Keap1 BTB/POZ dimerization function is required to sequester Nrf2 in cytoplasm, $J$ Biol Chem 277, 3654436552.

148. Hayes, J. D., McMahon, M., Chowdhry, S., and Dinkova-Kostova, A. T. (2010) Cancer chemoprevention mechanisms mediated through the Keap1-Nrf2 pathway, Antioxid Redox Signal 13, 1713-1748.

149. Dinkova-Kostova, A. T., Holtzclaw, W. D., and Wakabayashi, N. (2005) Keap1, the sensor for electrophiles and oxidants that regulates the phase 2 response, is a zinc metalloprotein, Biochemistry 44, 6889-6899.

150. Woycechowsky, K. J., and Raines, R. T. (2003) The CXC motif: a functional mimic of protein disulfide isomerase, Biochemistry 42, 5387-5394.

151. Dinkova-Kostova, A. T., Holtzclaw, W. D., and Kensler, T. W. (2005) The role of Keap1 in cellular protective responses, Chem Res Toxicol 18, 1779-1791.

152. Kobayashi, M., and Yamamoto, M. (2006) Nrf2-Keap1 regulation of cellular defense mechanisms against electrophiles and reactive oxygen species, $A d v$ Enzyme Regul 46, 113-140.

153. Turpaev, K. T. (2013) Keap1-Nrf2 signaling pathway: mechanisms of regulation and role in protection of cells against toxicity caused by xenobiotics and electrophiles, Biochemistry (Mosc) 78, 111-126.

154. Holland, R., Hawkins, A. E., Eggler, A. L., Mesecar, A. D., Fabris, D., and Fishbein, J. C. (2008) Prospective type 1 and type 2 disulfides of Keap1 protein, Chem Res Toxicol 21, 2051-2060. 
155. Sekhar, K. R., Rachakonda, G., and Freeman, M. L. (2010) Cysteine-based regulation of the CUL3 adaptor protein Keap1, Toxicol Appl Pharmacol 244, 21-26.

156. Zhang, D. D., and Hannink, M. (2003) Distinct cysteine residues in Keap1 are required for Keap1-dependent ubiquitination of Nrf2 and for stabilization of Nrf2 by chemopreventive agents and oxidative stress, Mol Cell Biol 23, 81378151.

157. Levonen, A. L., Landar, A., Ramachandran, A., Ceaser, E. K., Dickinson, D. A., Zanoni, G., Morrow, J. D., and Darley-Usmar, V. M. (2004) Cellular mechanisms of redox cell signalling: role of cysteine modification in controlling antioxidant defences in response to electrophilic lipid oxidation products, Biochem J 378, 373-382.

158. Wakabayashi, N., Dinkova-Kostova, A. T., Holtzclaw, W. D., Kang, M. I., Kobayashi, A., Yamamoto, M., Kensler, T. W., and Talalay, P. (2004) Protection against electrophile and oxidant stress by induction of the phase 2 response: fate of cysteines of the Keap1 sensor modified by inducers, Proc Natl Acad Sci U S A 101, 2040-2045.

159. Yamamoto, T., Suzuki, T., Kobayashi, A., Wakabayashi, J., Maher, J., Motohashi, H., and Yamamoto, M. (2008) Physiological significance of reactive cysteine residues of Keap1 in determining Nrf2 activity, Mol Cell Biol 28, 27582770. 
160. Wilson, L. A., Gemin, A., Espiritu, R., and Singh, G. (2005) ets-1 is transcriptionally up-regulated by $\mathrm{H}_{2} \mathrm{O}_{2}$ via an antioxidant response element, Faseb J 19, 2085-2087.

161. Ishii, T., Itoh, K., Takahashi, S., Sato, H., Yanagawa, T., Katoh, Y., Bannai, S., and Yamamoto, M. (2000) Transcription factor Nrf2 coordinately regulates a group of oxidative stress-inducible genes in macrophages, $J$ Biol Chem 275, 16023-16029.

162. Fourquet, S., Guerois, R., Biard, D., and Toledano, M. B. (2010) Activation of NRF2 by nitrosative agents and $\mathrm{H} 2 \mathrm{O} 2$ involves KEAP1 disulfide formation, $J$ Biol Chem 285, 8463-8471.

163. Kobayashi, M., Li, L., Iwamoto, N., Nakajima-Takagi, Y., Kaneko, H., Nakayama, Y., Eguchi, M., Wada, Y., Kumagai, Y., and Yamamoto, M. (2009) The antioxidant defense system Keap1-Nrf2 comprises a multiple sensing mechanism for responding to a wide range of chemical compounds, Mol Cell Biol 29, 493-502.

164. Baird, L., Lleres, D., Swift, S., and Dinkova-Kostova, A. T. (2013) Regulatory flexibility in the Nrf2-mediated stress response is conferred by conformational cycling of the Keap1-Nrf2 protein complex, Proc Natl Acad Sci U S A 110, $15259-15264$.

165. Winterbourn, C. C. (2014) The challenges of using fluorescent probes to detect and quantify specific reactive oxygen species in living cells, Biochim Biophys Acta $1840,730-738$. 
166. Brejc, K., Sixma, T. K., Kitts, P. A., Kain, S. R., Tsien, R. Y., Ormo, M., and Remington, S. J. (1997) Structural basis for dual excitation and photoisomerization of the Aequorea victoria green fluorescent protein, Proc Natl Acad Sci U S A 94, 2306-2311.

167. Elsliger, M. A., Wachter, R. M., Hanson, G. T., Kallio, K., and Remington, S. J. (1999) Structural and spectral response of green fluorescent protein variants to changes in pH, Biochemistry 38, 5296-5301.

168. Heim, R., Cubitt, A. B., and Tsien, R. Y. (1995) Improved green fluorescence, Nature 373, 663-664.

169. Hanson, G. T., Aggeler, R., Oglesbee, D., Cannon, M., Capaldi, R. A., Tsien, R. Y., and Remington, S. J. (2004) Investigating mitochondrial redox potential with redox-sensitive green fluorescent protein indicators, J Biol Chem 279, 1304413053.

170. Dooley, C. T., Dore, T. M., Hanson, G. T., Jackson, W. C., Remington, S. J., and Tsien, R. Y. (2004) Imaging dynamic redox changes in mammalian cells with green fluorescent protein indicators, J Biol Chem 279, 22284-22293.

171. Meyer, A. J., Brach, T., Marty, L., Kreye, S., Rouhier, N., Jacquot, J. P., and Hell, R. (2007) Redox-sensitive GFP in Arabidopsis thaliana is a quantitative biosensor for the redox potential of the cellular glutathione redox buffer, Plant $J$ $52,973-986$.

172. Cannon, M. B., and Remington, S. J. (2006) Re-engineering redox-sensitive green fluorescent protein for improved response rate, Protein Sci 15, 45-57. 
173. Gutscher, M., Pauleau, A. L., Marty, L., Brach, T., Wabnitz, G. H., Samstag, Y., Meyer, A. J., and Dick, T. P. (2008) Real-time imaging of the intracellular glutathione redox potential, Nat Methods 5, 553-559.

174. Gutscher, M., Sobotta, M. C., Wabnitz, G. H., Ballikaya, S., Meyer, A. J., Samstag, Y., and Dick, T. P. (2009) Proximity-based protein thiol oxidation by $\mathrm{H}_{2} \mathrm{O}_{2}$-scavenging peroxidases, $J$ Biol Chem 284, 31532-31540.

175. Belousov, V. V., Fradkov, A. F., Lukyanov, K. A., Staroverov, D. B., Shakhbazov, K. S., Terskikh, A. V., and Lukyanov, S. (2006) Genetically encoded fluorescent indicator for intracellular hydrogen peroxide, Nat Methods 3, 281-286.

176. Meyer, A. J., and Dick, T. P. (2010) Fluorescent protein-based redox probes, Antioxid Redox Signal 13, 621-650.

177. Lukyanov, K. A., and Belousov, V. V. (2014) Genetically encoded fluorescent redox sensors, Biochim Biophys Acta 1840, 745-756.

178. Hansen, R. E., and Winther, J. R. (2009) An introduction to methods for analyzing thiols and disulfides: Reactions, reagents, and practical considerations, Anal Biochem 394, 147-158.

179. Leichert, L. I., and Jakob, U. (2004) Protein thiol modifications visualized in vivo, PLoS Biol 2, e333.

180. Held, J. M., and Gibson, B. W. (2012) Regulatory control or oxidative damage? Proteomic approaches to interrogate the role of cysteine oxidation status in biological processes, Mol Cell Proteomics 11, R111 013037. 
181. Seo, Y. H., and Carroll, K. S. (2009) Facile synthesis and biological evaluation of a cell-permeable probe to detect redox-regulated proteins, Bioorg Med Chem Lett 19, 356-359.

182. Reddie, K. G., Seo, Y. H., Muse Iii, W. B., Leonard, S. E., and Carroll, K. S. (2008) A chemical approach for detecting sulfenic acid-modified proteins in living cells, Mol Biosyst 4, 521-531.

183. Leonard, S. E., Reddie, K. G., and Carroll, K. S. (2009) Mining the thiol proteome for sulfenic acid modifications reveals new targets for oxidation in cells, ACS Chem Biol 4, 783-799.

184. Paulsen, C. E., Truong, T. H., Garcia, F. J., Homann, A., Gupta, V., Leonard, S. E., and Carroll, K. S. (2011) Peroxide-dependent sulfenylation of the EGFR catalytic site enhances kinase activity, Nat Chem Biol 8, 57-64.

185. Poole, L. B., Zeng, B. B., Knaggs, S. A., Yakubu, M., and King, S. B. (2005) Synthesis of chemical probes to map sulfenic acid modifications on proteins, Bioconjugate chemistry 16, 1624-1628.

186. Poole, L. B., Klomsiri, C., Knaggs, S. A., Furdui, C. M., Nelson, K. J., Thomas, M. J., Fetrow, J. S., Daniel, L. W., and King, S. B. (2007) Fluorescent and affinity-based tools to detect cysteine sulfenic acid formation in proteins, Bioconjugate chemistry 18, 2004-2017.

187. Charles, R. L., Schroder, E., May, G., Free, P., Gaffney, P. R., Wait, R., Begum, S., Heads, R. J., and Eaton, P. (2007) Protein sulfenation as a redox sensor: proteomics studies using a novel biotinylated dimedone analogue, Mol Cell Proteomics 6, 1473-1484. 
188. Qian, J., Wani, R., Klomsiri, C., Poole, L. B., Tsang, A. W., and Furdui, C. M. (2012) A simple and effective strategy for labeling cysteine sulfenic acid in proteins by utilization of beta-ketoesters as cleavable probes, Chem Commun (Camb) 48, 4091-4093.

189. Seo, Y. H., and Carroll, K. S. (2009) Profiling protein thiol oxidation in tumor cells using sulfenic acid-specific antibodies, Proc Natl Acad Sci U S A 106, $16163-16168$.

190. Maller, C., Schroder, E., and Eaton, P. (2011) Glyceraldehyde 3-phosphate dehydrogenase is unlikely to mediate hydrogen peroxide signaling: studies with a novel anti-dimedone sulfenic acid antibody, Antioxid Redox Signal 14, 49-60.

191. Cumming, R. C., Andon, N. L., Haynes, P. A., Park, M., Fischer, W. H., and Schubert, D. (2004) Protein disulfide bond formation in the cytoplasm during oxidative stress, J Biol Chem 279, 21749-21758.

192. Jaffrey, S. R., Erdjument-Bromage, H., Ferris, C. D., Tempst, P., and Snyder, S. H. (2001) Protein S-nitrosylation: a physiological signal for neuronal nitric oxide, Nat Cell Biol 3, 193-197.

193. Wang, X., Kettenhofen, N. J., Shiva, S., Hogg, N., and Gladwin, M. T. (2008) Copper dependence of the biotin switch assay: modified assay for measuring cellular and blood nitrosated proteins, Free Radic Biol Med 44, 1362-1372.

194. Giustarini, D., Dalle-Donne, I., Colombo, R., Milzani, A., and Rossi, R. (2008) Is ascorbate able to reduce disulfide bridges? A cautionary note, Nitric oxide : biology and chemistry / official journal of the Nitric Oxide Society 19, 252-258. 
195. Saurin, A. T., Neubert, H., Brennan, J. P., and Eaton, P. (2004) Widespread sulfenic acid formation in tissues in response to hydrogen peroxide, Proc Natl Acad Sci U S A 101, 17982-17987.

196. Lind, C., Gerdes, R., Hamnell, Y., Schuppe-Koistinen, I., von Lowenhielm, H. B., Holmgren, A., and Cotgreave, I. A. (2002) Identification of Sglutathionylated cellular proteins during oxidative stress and constitutive metabolism by affinity purification and proteomic analysis, Arch Biochem Biophys 406, 229-240.

197. Cleland, W. W. (1964) Dithiothreitol, a New Protective Reagent for Sh Groups, Biochemistry 3, 480-482.

198. Han, J. C., and Han, G. Y. (1994) A procedure for quantitative determination of tris(2-carboxyethyl)phosphine, an odorless reducing agent more stable and effective than dithiothreitol, Anal Biochem 220, 5-10.

199. Cline, D. J., Redding, S. E., Brohawn, S. G., Psathas, J. N., Schneider, J. P., and Thorpe, C. (2004) New water-soluble phosphines as reductants of peptide and protein disulfide bonds: reactivity and membrane permeability, Biochemistry 43, 15195-15203.

200. Le Moan, N., Clement, G., Le Maout, S., Tacnet, F., and Toledano, M. B. (2006) The Saccharomyces cerevisiae proteome of oxidized protein thiols: contrasted functions for the thioredoxin and glutathione pathways, J Biol Chem 281, 10420-10430. 
201. Baty, J. W., Hampton, M. B., and Winterbourn, C. C. (2005) Proteomic detection of hydrogen peroxide-sensitive thiol proteins in Jurkat cells, Biochem J $389,785-795$.

202. Hao, G., Derakhshan, B., Shi, L., Campagne, F., and Gross, S. S. (2006) SNOSID, a proteomic method for identification of cysteine S-nitrosylation sites in complex protein mixtures, Proc Natl Acad Sci U S A 103, 1012-1017.

203. Forrester, M. T., Thompson, J. W., Foster, M. W., Nogueira, L., Moseley, M. A., and Stamler, J. S. (2009) Proteomic analysis of S-nitrosylation and denitrosylation by resin-assisted capture, Nat Biotechnol 27, 557-559.

204. Foster, M. W. (2012) Methodologies for the characterization, identification and quantification of S-nitrosylated proteins, Biochim Biophys Acta 1820, 675-683.

205. Bechtold, E., and King, S. B. (2012) Chemical methods for the direct detection and labeling of S-nitrosothiols, Antioxid Redox Signal 17, 981-991.

206. Martinez-Acedo, P., Nunez, E., Gomez, F. J., Moreno, M., Ramos, E., Izquierdo-Alvarez, A., Miro-Casas, E., Mesa, R., Rodriguez, P., Martinez-Ruiz, A., Dorado, D. G., Lamas, S., and Vazquez, J. (2012) A novel strategy for global analysis of the dynamic thiol redox proteome, Mol Cell Proteomics 11, 800-813.

207. Gygi, S. P., Rist, B., Gerber, S. A., Turecek, F., Gelb, M. H., and Aebersold, R. (1999) Quantitative analysis of complex protein mixtures using isotope-coded affinity tags, Nat Biotechnol 17, 994-999.

208. Sethuraman, M., McComb, M. E., Huang, H., Huang, S., Heibeck, T., Costello, C. E., and Cohen, R. A. (2004) Isotope-coded affinity tag (ICAT) approach to 
redox proteomics: identification and quantitation of oxidant-sensitive cysteine thiols in complex protein mixtures, J Proteome Res 3, 1228-1233.

209. Sethuraman, M., Clavreul, N., Huang, H., McComb, M. E., Costello, C. E., and Cohen, R. A. (2007) Quantification of oxidative posttranslational modifications of cysteine thiols of p21ras associated with redox modulation of activity using isotope-coded affinity tags and mass spectrometry, Free Radic Biol Med 42, 823-829.

210. Leichert, L. I., Gehrke, F., Gudiseva, H. V., Blackwell, T., Ilbert, M., Walker, A. K., Strahler, J. R., Andrews, P. C., and Jakob, U. (2008) Quantifying changes in the thiol redox proteome upon oxidative stress in vivo, Proc Natl Acad Sci USA $105,8197-8202$.

211. Garcia-Santamarina, S., Boronat, S., Espadas, G., Ayte, J., Molina, H., and Hidalgo, E. (2011) The oxidized thiol proteome in fission yeast--optimization of an ICAT-based method to identify $\mathrm{H}_{2} \mathrm{O}_{2}$-oxidized proteins, J Proteomics 74 , 2476-2486.

212. Brandes, N., Reichmann, D., Tienson, H., Leichert, L. I., and Jakob, U. (2011) Using quantitative redox proteomics to dissect the yeast redoxome, $J$ Biol Chem 286, 41893-41903.

213. Knoefler, D., Thamsen, M., Koniczek, M., Niemuth, N. J., Diederich, A. K., and Jakob, U. (2012) Quantitative in vivo redox sensors uncover oxidative stress as an early event in life, Mol Cell 47, 767-776. 
214. Kumsta, C., Thamsen, M., and Jakob, U. (2011) Effects of oxidative stress on behavior, physiology, and the redox thiol proteome of Caenorhabditis elegans, Antioxid Redox Signal 14, 1023-1037.

215. Hansen, R. E., Roth, D., and Winther, J. R. (2009) Quantifying the global cellular thiol-disulfide status, Proc Natl Acad Sci U S A 106, 422-427.

216. Boersema, P. J., Raijmakers, R., Lemeer, S., Mohammed, S., and Heck, A. J. (2009) Multiplex peptide stable isotope dimethyl labeling for quantitative proteomics, Nat Protoc 4, 484-494. 


\section{FIGURE LEGENDS}

Figure 1. Scheme representing different oxidation states of a sulfur atom upon $\mathrm{H}_{2} \mathrm{O}_{2}$ dependent oxidation. After exposure to $\mathrm{H}_{2} \mathrm{O}_{2}$, thiol groups are initially oxidized to a sulfenic acid form. This species is highly unstable, readily reacting with another proximal thiol to form a disulfide bond. In a cellular environment, disulfide bonds can be reduced to the thiol form by the enzymatic activities of the thioredoxin or the GSH/glutaredoxin systems. In the presence of more $\mathrm{H}_{2} \mathrm{O}_{2}$, sulfenic acid can be further oxidized to sulfinic or sulfonic acids, which in general are irreversible modifications that can not be repaired within cells.

Figure 2. Systems of thiol redox control. (A) Trx system. Disulfide bonds in proteins can be recycled to their reduced form with electrons provided by NADPH through a series of reactions that involve redox cycling of thioredoxin (Trx) and thioredoxin reductase (TrxR). (B) GSH/Grx system. Upper panel, dithiol mechanism. Disulfide bonds in proteins can be recycled to their reduced form with electrons provided by NADPH through a series of reactions that involve redox cycling of glutaredoxin (Grx), glutathione (GSH) and GSH reductase (GSHR). Lower panel, monothiol mechanism. Disulfides between GSH and proteins only require the N-terminal Cys of Grx to be reduced. The non-GSH molecule is the best leaving group, while GSH forms a mixed disulfide with Grx, which is then reduced by a second molecule of GSH. Electrons are provided by NADPH through GSHR.

Figure 3. Prokaryotic and eukaryotic $\mathrm{H}_{2} \mathrm{O}_{2}$-activated transcription factors. (A) $\mathrm{H}_{2} \mathrm{O}_{2}$ sensing mechanism of OxyR. Under basal conditions, reduced OxyR is bound to promoteroperon regions of target genes with low affinity. Upon $\mathrm{H}_{2} \mathrm{O}_{2}$ exposure, Cys 199 is first oxidized to sulfenic acid and then forms a disulfide bond with Cys208. The resulting 
conformational change in OxyR increases its binding affinity to DNA, resulting in the activation of target genes. (B) Proposed model of Yap1 sensing mechanism. Under basal conditions, Yap1 is kept in the cytoplasm in a reduced form bound to Orp1. Upon $\mathrm{H}_{2} \mathrm{O}_{2}$ exposure, the GPx Gpx3/Orp1 Cys36 is first oxidized to sulfenic form. This oxidized Cys forms an intermolecular disulfide bond with Yap1 Cys303, which then, by a disulfide exchange reaction is converted in a Yap1 intramolecular disulfide bond between Cys303 and Cys598. The resulting conformational change masks the Yap1 C-terminal NES triggering the nuclear accumulation of Yap1 which can bind to target genes. Further oxidation to yield additional disulfide bonds in Yap1 has also been proposed (see text for details) (C) Pap1 sensing mechanism of $\mathrm{H}_{2} \mathrm{O}_{2}$. Under basal conditions, the Prx Tpx1 reduces $\mathrm{H}_{2} \mathrm{O}_{2}$ and it is recycled by Trx1. Upon mild exposure to $\mathrm{H}_{2} \mathrm{O}_{2}$, oxidized Tpx1 exceeds available reduced Trx1 and Pap1 behaves as an alternative electron donor for Tpx1. Tpx1 may oxidize a Pap1 nCRD Cys (Cys 285 or Cys278) by either a mechanism based in a SOH to disulfide transfer or through a disulfide-to- disulfide isomerization (see text for details). As in the case of Yap1, Pap1 accumulates in the nucleus after disulfide bond formation. Probably, two disulfides are formed upon $\mathrm{H}_{2} \mathrm{O}_{2}$ stress. (D) Proposed activation mechanism of Nrf2 activation by $\mathrm{H}_{2} \mathrm{O}_{2}$. Newly transcribed $\mathrm{Nrf} 2$ binds to a Keap1 dimer in a conformation that favors Nrf2 ubiquitination by Keap1 bound Cul3 which results in Nrf2 proteasomal degradation. Upon exposure to $\mathrm{H}_{2} \mathrm{O}_{2}$, Keap1 Cys151 would be oxidized and form a disulfide bond with Cys151 of the other subunit of the dimer. The resulting conformational change would prevent Nrf2 ubiquitination by $\mathrm{Cul} 3$ and subsequent proteasomal degradation. Since Nrf2 would still be bound to Keap1, newly translated Nrf2 would be able to translocate to the nucleus and activate the transcription of target genes. 
Figure 4. Genetically-encoded redox probes. (A) Mechanism of Grx1-roGFP2. Upon an increase in the oxidized fraction of GSH (GSSG), Grx1 forms a mixed disulfide intermediate with GSH. This reacts with one of the thiols in roGFP2, which consequently becomes Sglutathionylated. In the last step, there is a rearrangement of the S-glutathionylated form of roGFP2 yielding an internal disulfide bond. Oxidation of the probe causes changes in the fluorescent excitation maxima, which can be measured by flow cytometry or confocal microscopy. (B) Mechanism of roGFP2-Orp1. Upon $\mathrm{H}_{2} \mathrm{O}_{2}$ treatment, Orp1 is initially oxidized to $\mathrm{SOH}$, which readily forms an intramolecular disulfide bond with another Cys of Orp1. This disulfide is then transferred to roGFP2 through a thiol-disulfide exchange. Again, oxidation of the probe can be measured by changes in the excitation fluorescence. (C) Mechanism of HyPer probe. Cys199 within OxyR-RD reacts with $\mathrm{H}_{2} \mathrm{O}_{2}$ to initially form a SOH. This rapidly condenses with Cys208 located in the same domain, but that it is separated by cpYFP in the probe. Disulfide bond formation leads to an important conformational change resulting in measurable fluorescent changes in living cells.

Figure 5. ICAT-based gel free approach to study reversibly oxidized thiol proteomes. TCA protein extracts are prepared from condition 1 and condition 2 cells. Thiols in extracts are alkylated with iodoacetamide (IAM). Upon reduction of reversible oxidized thiol forms with a reducing agent (TCEP), newly formed thiols are alkylated with either light $\left(\mathrm{B}-{ }^{12} \mathrm{C}-\mathrm{IAM}\right.$, extracts from condition 1) or with heavy $\left(\mathrm{B}-{ }^{13} \mathrm{C}-\mathrm{IAM}\right.$, extracts from condition 2) ICAT reagents. Labeled protein extracts are then mixed and trypsinized. ICAT-labeled peptides are enriched by affinity purification, fractionated by liquid chromatography and analyzed by mass spectrometry (LC-MS/MS). For each peptide a ratio of Cys oxidation is obtained by comparing condition 2 versus condition 1. To quantify individual concentrations of protein levels an additional step of protein quantification can be performed. In this case, N-terminal 
labeling with dimethyl or iTRAQ derivatives is proposed. To do so, total extracts are independently trypsinized, peptides are isotopically labeled at their N-terminal groups, mixed, fractionated by liquid chromatography and analyzed by mass spectrometry (LCMS/MS). 


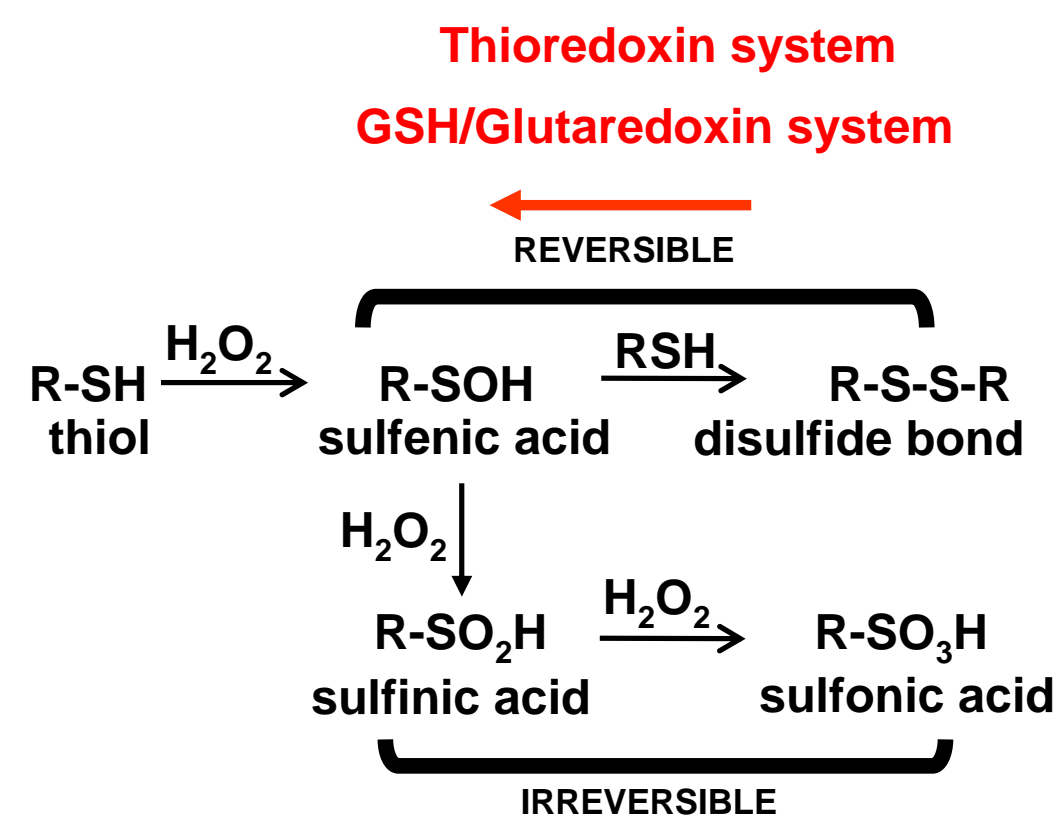

Garcia-Santamarina et al. Fig. 1 
A Trx system

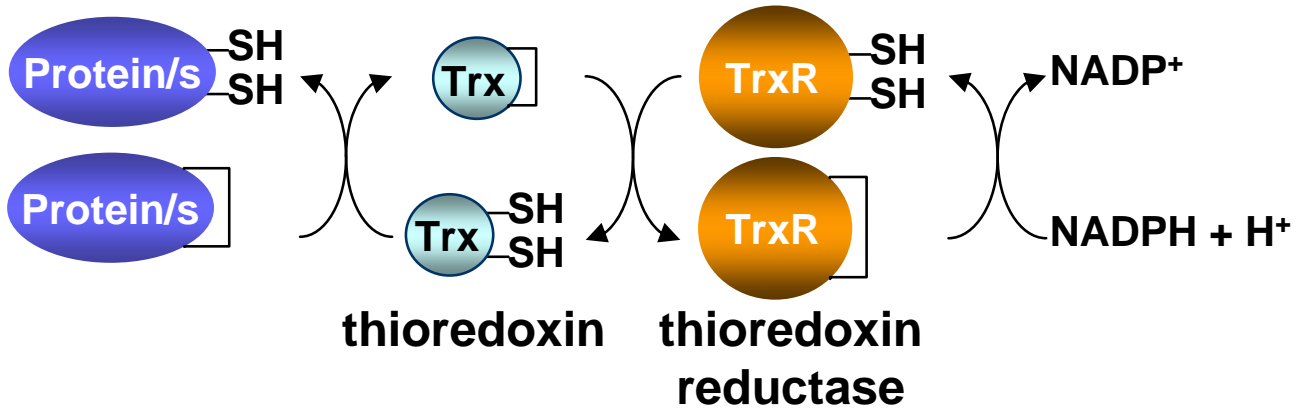

B GSH/Grx system

Dithiol mechanism

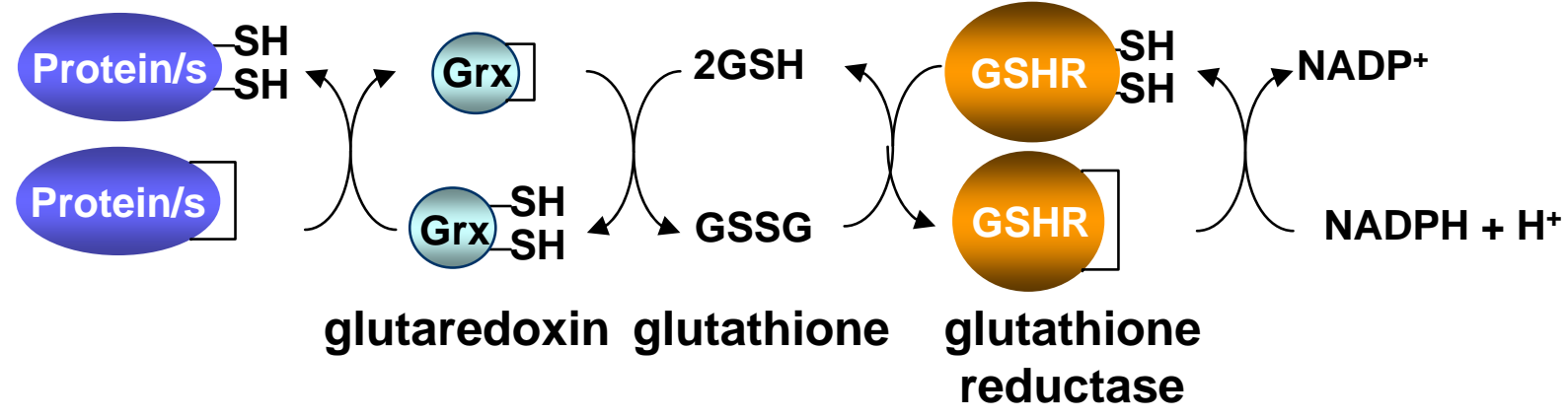

Monothiol mechanism

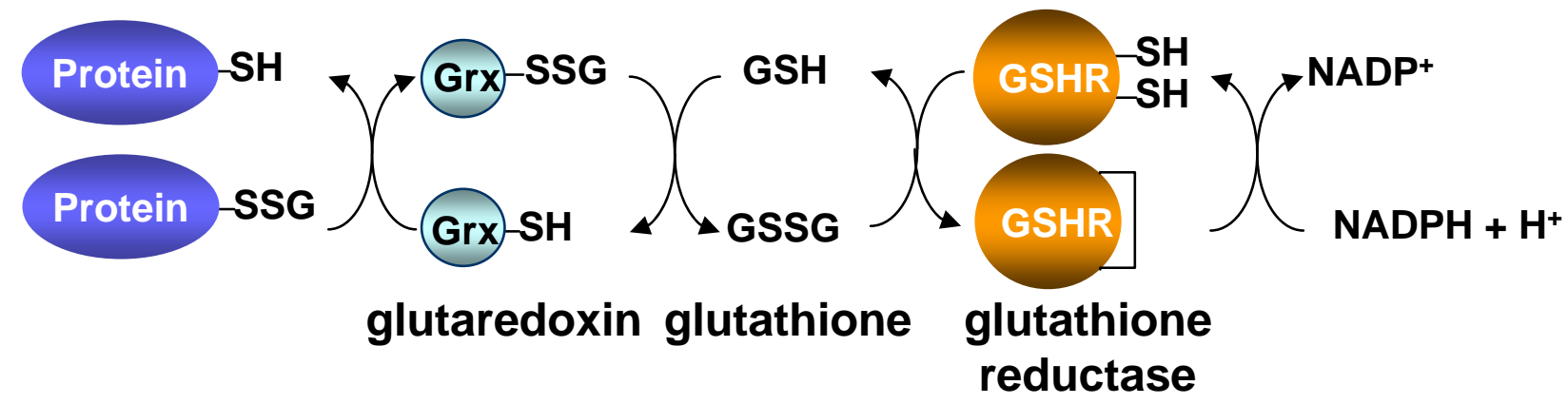

Garcia-Santamarina et al. Fig. 2 


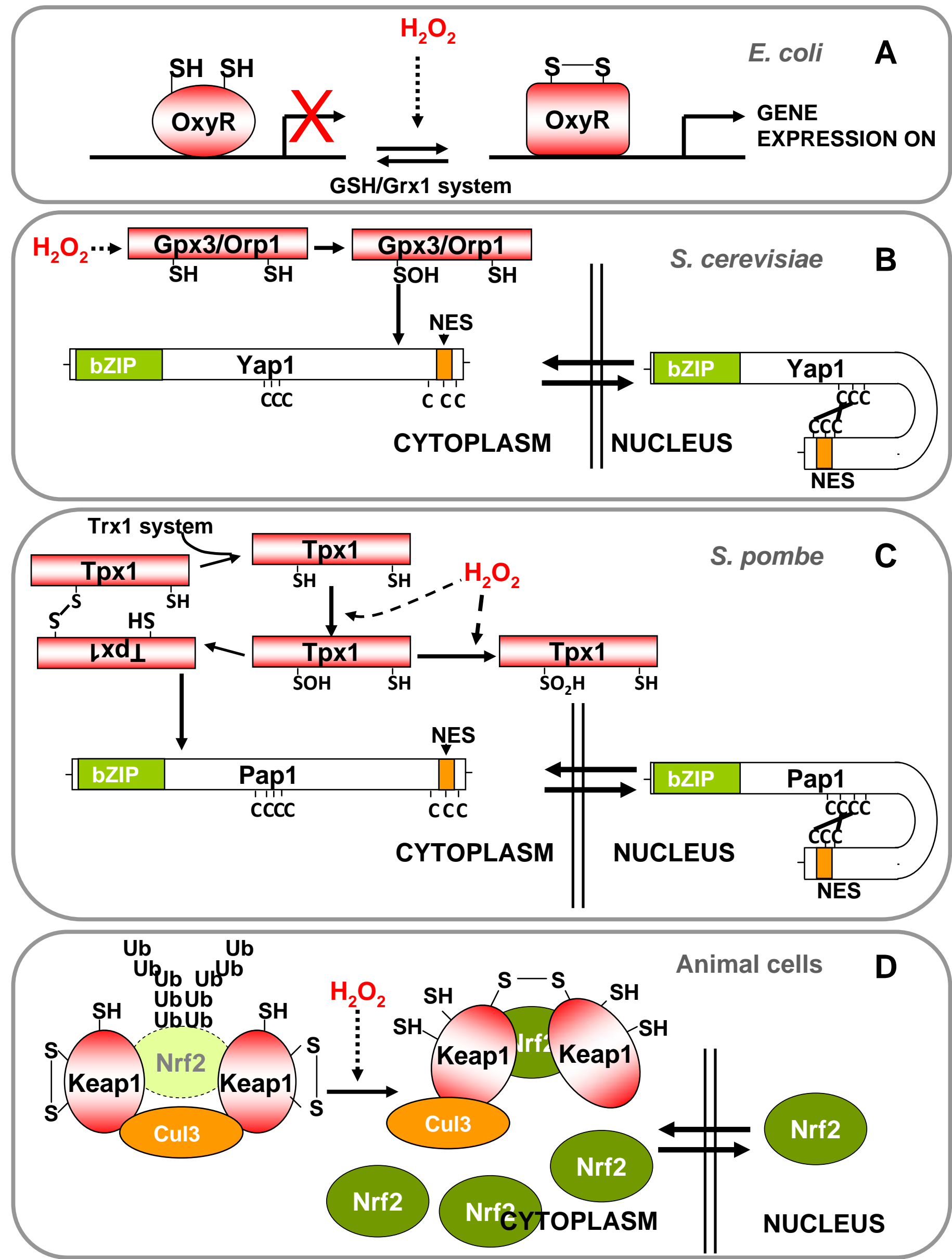

Garcia-Santamarina et al. Fig. 3 
A

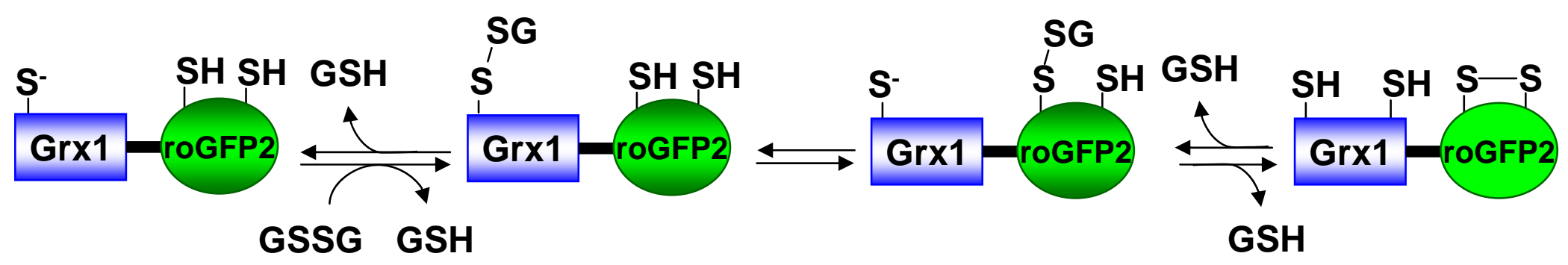

B

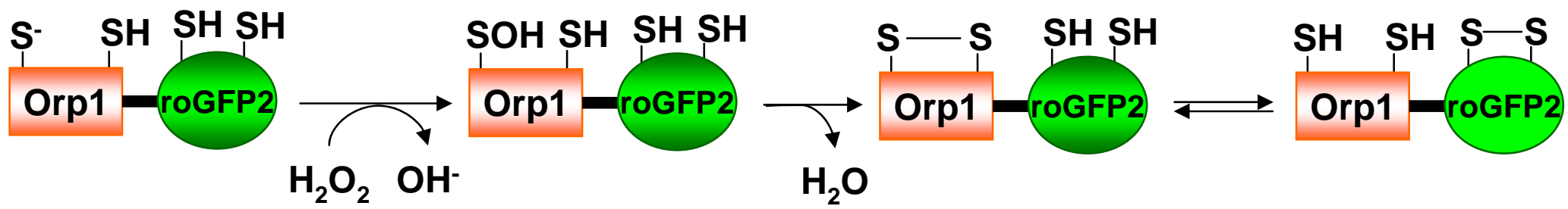

C

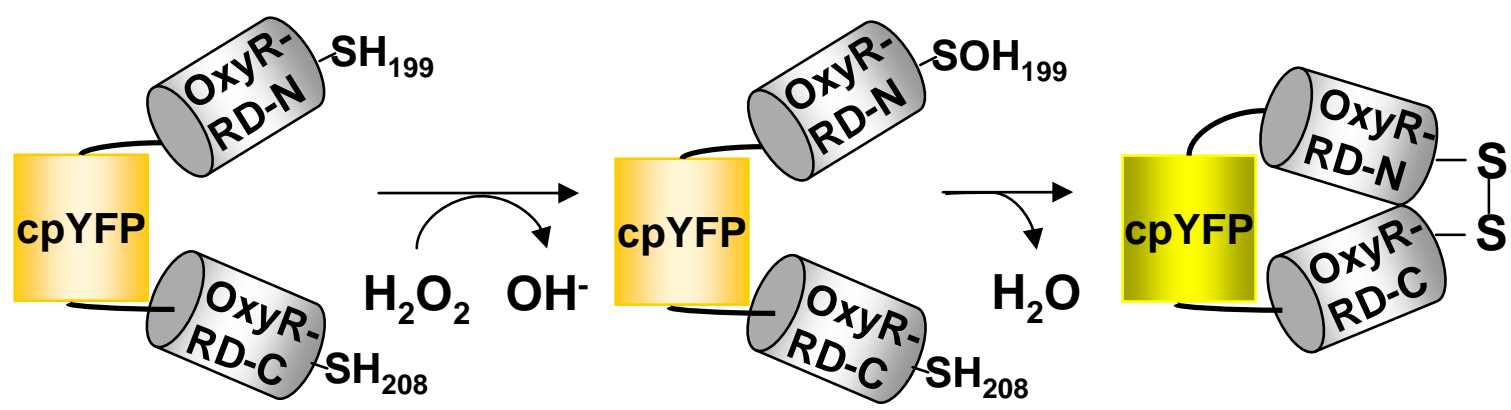

Garcia-Santamarina et al. Fig. 4 

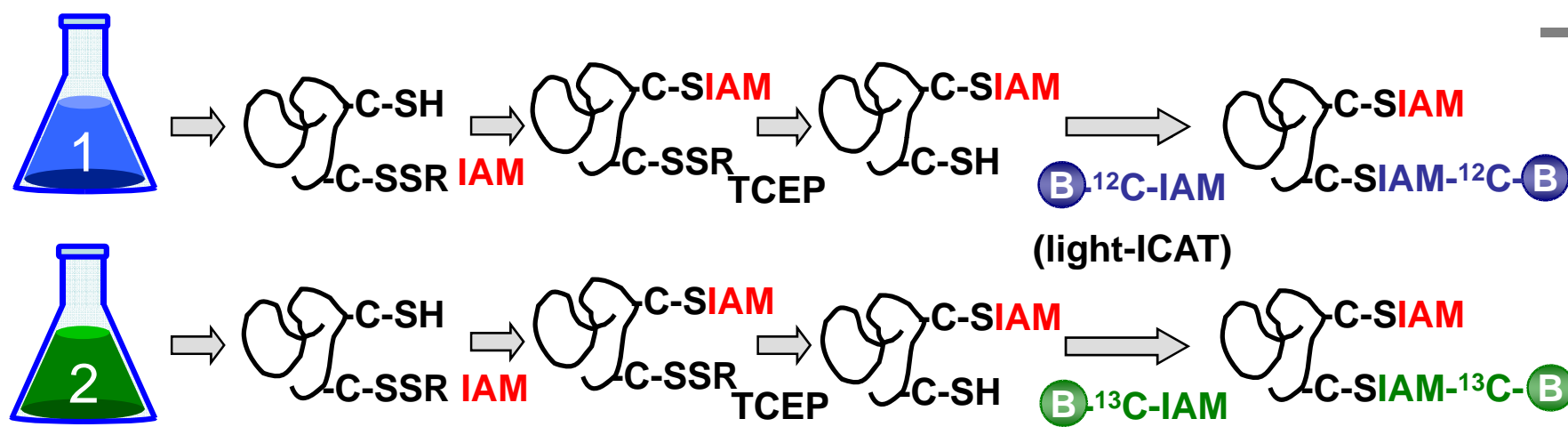

(light-ICAT)

A addition to cell cultures extracts

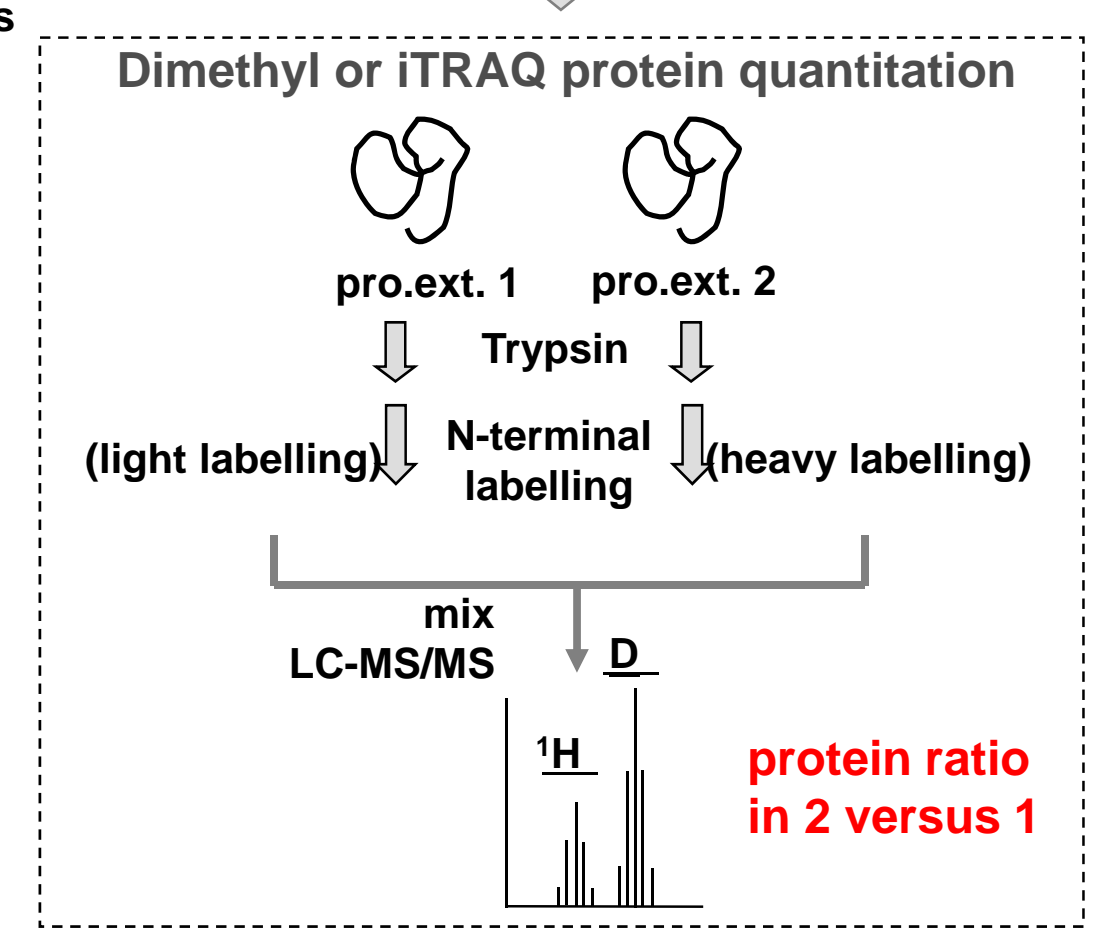

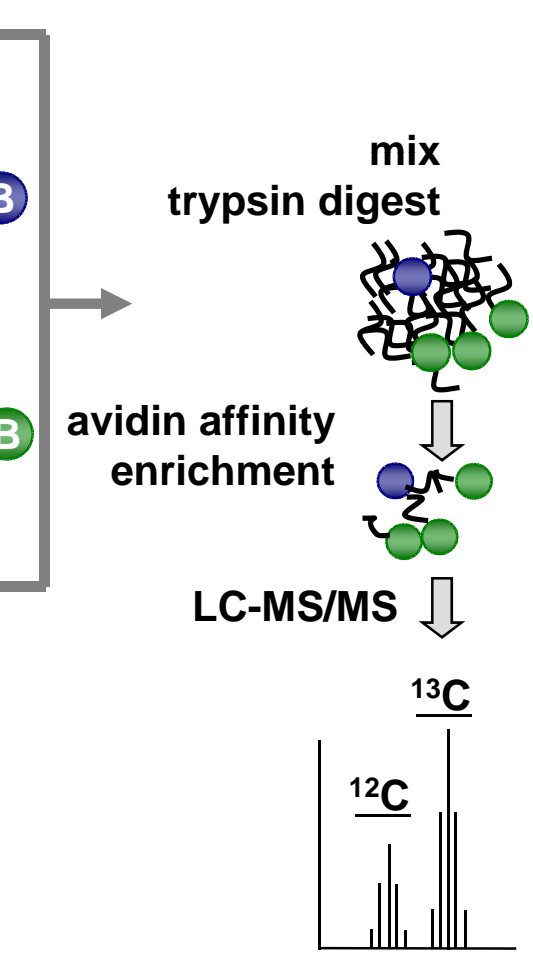

Cys oxidation ratio in 2 versus 1

Garcia-Santamarina et al. Fig. 5 